\title{
Performance of Landsat-8 and Sentinel-2 surface reflectance products for river remote sensing retrievals of chlorophyll- $a$ and turbidity
}

\author{
Catherine Kuhn ${ }^{\mathrm{a}, *}$, Aline de Matos Valerio ${ }^{\mathrm{b}}$, Nick Ward ${ }^{\mathrm{c}, \mathrm{d}}$, Luke Loken ${ }^{\mathrm{e}, \mathrm{f}}$, \\ Henrique Oliveira Sawakuchi ${ }^{g, h}$, Milton Kampel ${ }^{\mathrm{b}}$, Jeffrey Richey ${ }^{\mathrm{i}}$, Philipp Stadler, \\ John Crawford ${ }^{\mathrm{k}}$, Rob Striegl ${ }^{\mathrm{k}}$, Eric Vermote ${ }^{1}$, Nima Pahlevan ${ }^{1, \mathrm{~m}}$, David Butman ${ }^{\mathrm{a}, \mathrm{n}}$ \\ ${ }^{a}$ Department of Forestry and Environmental Science, University of Washington, Seattle, WA, USA \\ ${ }^{\mathrm{b}}$ Divisão de Sensoriamento Remoto, Instituto Nacional de Pesquisas Espaciais, São José dos Campos, São Paulo, Brazil \\ ${ }^{\mathrm{c}}$ Marine Sciences Laboratory, Pacific Northwest National Laboratory, Sequim, WA, USA \\ ${ }^{\mathrm{d}}$ School of Oceanography, University of Washington, Seattle, WA, USA \\ ${ }^{\mathrm{e}}$ U.S. Geological Survey, Wisconsin Water Science Center, Middleton, WI, USA \\ ${ }^{\mathrm{f}}$ Center for Limnology, University of Wisconsin-Madison, Madison, WI, USA \\ ${ }^{g}$ Centro de Energia Nuclear na Agricultura, Universidade de São Paulo, Piracicaba, São Paulo, Brazil \\ ${ }^{\mathrm{h}}$ Department of Ecology and Environmental Science, Umeå Universitet, KBC-huset, Linnaeus väg 6, 90187 Umeå, Sweden \\ ${ }^{\mathrm{i}}$ School of Oceanography, University of Washington, Seattle, WA, USA \\ ${ }^{\mathrm{j}}$ TU Wien, Centre for Water Resource Systems, Karlsplatz 13, A-1040 Vienna, Austria \\ ${ }^{\mathrm{k}}$ U.S. Geological Survey, Water Mission Area, USGS, Boulder, USA \\ ${ }^{1}$ NASA Goddard Space Flight Center, 8800 Greenbelt Road, Greenbelt, MD 20771, USA \\ ${ }^{\mathrm{m}}$ Science Systems and Applications Inc., 10210 Greenbelt Road, Lanham, MD, USA \\ ${ }^{\mathrm{n}}$ Department of Civil and Environment Engineering, University of Washington, Seattle, WA, USA
}

\section{A R T I C L E I N F O}

\section{Keywords:}

Atmospheric correction

Ocean color

Landsat-8

Sentinel-2

Mississippi River

Amazon River

Columbia River

Turbid waters

Inland waters

Remote Sensing

\begin{abstract}
A B S T R A C T
Rivers and other freshwater systems play a crucial role in ecosystems, industry, transportation and agriculture. Despite the $>40$ years of inland water observations made possible by optical remote sensing, a standardized reflectance product for inland waters is yet forthcoming. The aim of this work is to compare the standard USGS land surface reflectance product to two Landsat- 8 and Sentinel-2 aquatic remote sensing reflectance products over the Amazon, Columbia and Mississippi rivers. Landsat-8 reflectance products from all three routines are then evaluated for their comparative performance in retrieving chlorophyll-a and turbidity in reference to shipborne, underway in situ validation measurements. The land surface product shows the best agreement (4\% Mean Absolute Percent Difference) with field measurements of radiometry collected on the Amazon River and generates $36 \%$ higher reflectance values in the visible bands compared to aquatic methods (ACOLITE and SeaDAS) with larger differences between land and aquatic products observed in Sentinel-2 $\left(0.01 \mathrm{sr}^{-1}\right) \mathrm{compared} \mathrm{to}^{-1}$ Landsat-8 $\left(0.001 \mathrm{sr}^{-1}\right)$. Choice of atmospheric correction routine can bias Landsat-8 retrievals of chlorophyll-a and turbidity by as much as $59 \%$ and $35 \%$ respectively. Using a more restrictive time window for matching in situ and satellite imagery can reduce differences by $5-31 \%$ depending on correction technique. This work highlights the challenges of satellite retrievals over rivers and underscores the need for future optical and biogeochemical research aimed at improving our understanding of the absorbing and scattering properties of river water and their relationships to remote sensing reflectance.
\end{abstract}

\section{Introduction}

Rivers sustain terrestrial ecosystems and human communities (UN, 2009) yet are being transformed worldwide by anthropogenic pressures (Vörösmarty et al., 2010). Threats include harmful algal blooms, sediment loading, warming and eutrophication (Whitehead et al., 2009; Malmqvist et al., 2008). In terrestrial, ocean, coastal and lake ecosystems, satellites have been increasingly marshalled for ecological monitoring (Smith, 2003; Valerio et al., 2017), yet rivers have received relatively little attention in the field of aquatic remote sensing, in part

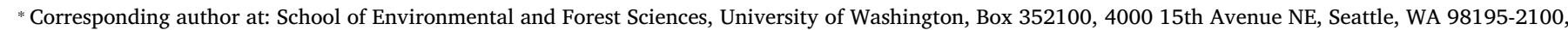
USA.

E-mail address: ckuhn@uw.edu (C. Kuhn).
} 
due to their small spatial scale $(<100 \mathrm{~km})$ and also because of their large dynamic range of optically significant constituents. Phytoplankton, chromophoric dissolved organic matter (CDOM), and nonalgal particles can all be present and do not necessarily co-vary. This optical complexity, when combined with rapid changes in river flow and chemistry, results in a challenging observational environment (Hestir et al., 2015).

The dynamic nature of rivers necessitates the ability to evaluate ecosystem characteristics beyond point samplings to understand spatiotemporal variation and monitor long-term changes. For example, products retrieved from satellites such as chlorophyll- $a$ (Chl- $a$ ), CDOM, and turbidity have been used for evaluating important processes/factors such as sediment and DOM transport (Griffin et al., 2018; Saraceno et al., 2009), total suspended matter (Shi et al., 2015) ecosystem productivity (Carr et al., 2006; Saba et al., 2011), and even greenhouse gas fluxes (Fay and McKinley, 2017) in the case of marine and lake settings, but these approaches are seldom applied to rivers.

Both atmospheric correction and bio-optical models are key processing steps to water color remote sensing (Ruddick et al., 2000). During atmospheric correction, remote sensing reflectance $\left(R_{r s}(\lambda)\right.$; $\mathrm{sr}^{-1}$ ), defined as the ratio of water-leaving radiance below the water surface to downwelling irradiance above the water surface (Mobley, 1999), is recovered from at-sensor measurements by correcting for surface effects and atmospheric influences. This process is paramount for the robust retrieval of chlorophyll- $a$, CDOM and sediment at regional and global scales (McCain et al., 2006) yet remains one of the largest sources of error and foremost challenges in aquatic remote sensing (Mobley et al., 2016; Mouw et al., 2015).

While sensor-specific atmospheric correction routines for land and ocean applications have existed for decades (Gordon and Wang, 1994), inland water techniques are still emerging. Atmospheric correction over water requires greater precision than over land because 70 to $90 \%$ of the top of the atmosphere signal over water is known to be from atmospheric effects and sun and sky glint from the water surface (Wang, 2010). In light of this challenge, the joint National Aeronautics and Space Administration (NASA) and United States Geologic Survey (USGS) Landsat-8 Surface Reflectance Code (LaSRC), while primarily designed for terrestrial applications, has been modified to include a routine over surface waters (Vermote et al., 2016). At coarser resolutions, significant progress has been made in developing specialized corrections for coastal ocean applications. For example, NASA's Ocean Color Biology Processing Group (OBPG) regularly generates atmospherically-corrected Level-2 products from ocean color sensors including the Moderate Resolution Imaging Spectroradiometer (MODIS) and Visible Infrared Imaging Radiometer Suite (VIIRS) (Barnes and $\mathrm{Hu}$, 2016; O'Reilly et al., 1998; Wang and Shi, 2007) using the SeaWiFS Data Analysis System (SeaDAS).

The large pixel size $(>250 \mathrm{~m})$ of standard ocean color products limits their use at smaller spatial scales relevant to inland waters (Mouw et al., 2015). While not designed for ocean color applications, moderate-resolution missions $(10-100 \mathrm{~m})$ such as the Operational Land Imager (OLI) on board NASA's Landsat-8 (L8) and the Multispectral Instrument (MSI) on board the European Space (ESA) Agency's Sentinel-2 (S2), abbreviated hereafter as L8 and S2, provide an improvement over prior generations of moderate-resolution sensors used for monitoring near-surface water constituents.

For example, Franz et al. (2015) demonstrated the atmospheric correction of L8 in SeaDAS over the Chesapeake Bay for the retrieval of Chl-a. Pahlevan et al. (2017b) used atmospherically-corrected S2 images to map total suspended sediment in moderately turbid coastal waters. Lymburner et al. (2016) used a land-based atmospheric correction of L8 over Australian lakes and produced reasonable estimates of surface reflectance, which were then successfully used to retrieve total suspended matter (TSM). L8-retrieved TSM values showed a strong correlation with in situ data, but the land-based atmospheric correction was thought to introduce a positive bias.
Surface reflectance over complex waters has also been estimated using a software platform called ACOLITE for both L8 (Vanhellemont and Ruddick, 2014) and S2 (Vanhellemont and Ruddick, 2016) for turbid coastal waters. Thus, the number of specialized atmospheric correction routines has increased substantially (Dörnhöfer and Oppelt, 2016) since the first ocean color correction was developed (Gordon, 1978) and performance comparisons over land are underway (Doxani et al., 2018). Despite this, few papers compare their merits (Hadjimitsis et al., 2004; Doxani et al., 2018; Martins et al., 2017) and standardized surface reflectance products are not yet available for inland water applications.

A second major barrier impeding our ability to evaluate water color retrievals is the limited number of concurrent, in situ, validation measurements (O'Reilly et al., 1998). Multi-parameter ship-borne sensing platforms are increasingly used in coastal and ocean settings to retrieve bio-optical properties (Werdell et al., 2013; Aiken and Hooker, 1997; Brewin et al., 2016; Matsuoka et al., 2016; Dall'Olmo et al., 2009; Slade et al., 2010; Fichot et al., 2015). These underway measurement systems allow for large-scale validation of satellite-based products. Underway measurements have expanded the possible scale of river observations, resulting in changes in our understanding of riverine carbon dynamics at the global scale (Sawakuchi et al., 2017). Conversely, in inland waters, especially rivers, the use of underway flow-through systems for calibration and validation of satellite products is still incipient.

In light of these advances, here we evaluate the potential of three atmospheric corrections to L8 and S2, validated with high-resolution underway measurements of river constituents, to develop space-based retrievals of Chl- $a$ and turbidity in large rivers. Our primary objective is to examine the influence of three atmospheric correction routines (LaSRC, SeaDAS, ACOLITE) on estimating these parameters.

To achieve this goal, we begin by analyzing surface reflectance estimates, abbreviated hereafter as $\mathrm{R}_{\mathrm{rs}}$ for readability, from three atmospheric correction routines and evaluating the differences in remote sensing reflectance spectra. We compare the reflectance spectra generated by this analysis to in-river field measurements as well as to satellite-derived spectra from the literature. We then examine the influence of these spectral differences on the performance of standard biooptical algorithms for Chl- $a$ and turbidity. Our goal is to examine how current remote sensing approaches may or may not suffice for estimating water constituents across a range of river conditions.

\section{Site description}

Continuous, underway data coincident to satellite overpasses were collected from the main stem of the Amazon, Columbia and Mississippi rivers (Table 1, Fig. 1). The rivers represent a natural gradient in water color from very clear to very turbid. The cruises are part of an ongoing effort (Stadler et al., 2018; Ward et al., 2018; Crawford et al., 2016, 2017) to characterize carbon cycling in major rivers using large-scale underway sampling transects.

\section{Methods}

The overarching methodological framework (Fig. 2d) for this study was to match satellite and in situ measurements for three optically diverse river systems ranging from the shallow and productive waters of the Mississippi (Fig. 2a) to the relatively clearer, deeper waters (Fig. 2b) of the Columbia river with the two cruises during Amazon High Water (HW) and Low Water (LW) acting as a very turbid endpoint (Fig. 2c).

\subsection{Underway river datasets for algorithm evaluation}

Custom, flow-through systems delivered river water on board from an average depth of $0.2 \mathrm{~m}$ where it passed through a series of optical sensors configured to log simultaneously with a GPS unit as described in Crawford et al. (2017, 2016); Turner et al. (2016); Ward et al. (2018). 
Table 1

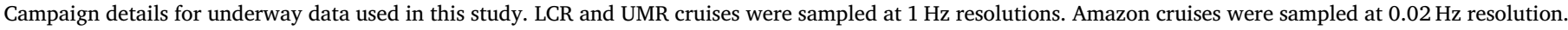
Counts $(\mathrm{N})$ are given for datasets after binning to 1-minute intervals but prior to filtering for quality control.

\begin{tabular}{|c|c|c|c|c|c|}
\hline Dataset & River and region & Period & Distance & Variable & $\mathrm{N}$ \\
\hline A-LW & Amazon Low Water, Lower Amazon, Brazil, South America & 2016-11-04-2016-11-09 & $\sim 526 \mathrm{~km}$ & Chl- $a^{\mathrm{a}}$, Turb $^{\mathrm{b}}, \mathrm{R}_{\mathrm{rs}}(\lambda)$ & 3838 \\
\hline A-HW & Amazon High Water, Lower Amazon, Brazil, South America & 2017-04-26-2017-05-02 & $\sim 526 \mathrm{~km}$ & Chl- $a$, Turb, $\mathrm{R}_{\mathrm{rs}}(\lambda)$ & 4299 \\
\hline LCR & Lower Columbia, USA, North America & 2016-07-12-2016-07-18 & $\sim 568 \mathrm{~km}$ & Chl- $a$, Turb & 1436 \\
\hline UMR & Upper Mississippi, USA, North America & $2015-08-01-2015-08-13$ & $1385 \mathrm{~km}$ & Chl- $a$, Turb & 4170 \\
\hline
\end{tabular}

a Chlorophyll- $a$ concentration $\left(\mathrm{mg} / \mathrm{m}^{3}\right)$.

b Turbidity (FNU).

Optical parameters measured included turbidity (FNU) (ISO-7027 method, $860 \pm 15 \mathrm{~nm}$ excitation, $90^{\circ}$ scattering) and Chl- $a$ fluorescence $\left(\mathrm{mg} \mathrm{m}^{-3}\right.$, excitation $470 \mathrm{~nm} \pm 15 \mathrm{~nm}$ and emissions \pm 685 $20 \mathrm{~nm}$ ), as measured by a Yellow Springs Instrument (YSI) EXO2 sonde. Fluorometers are well-suited for inline, large-scale mapping because of small sensor size and lower power requirements. Chlorophyll- $a$ fluorescence (Chl- $a$ ) is commonly held to be a proxy for chlorophyll- $a$ concentration. Known biases associated with fluorometric Chl- $a$ include interference from other bio-optical components like non-algal particles as well as variability in phytoplankton physiology and species composition which can cause changes in the fluorescence to Chl- $a$ ratio (Roesler et al., 2017; Mouw et al., 2013; Dierssen, 2010). Unfortunately, HPLC pigment data are not available so natural variations between Chl- $a$ concentrations and fluorescence for these large rivers remain to be studied. Turbidity, in its formal optical definition, refers to the amount of attenuation and backscattering of light due to suspended solids and dissolved load. Data were logged per second at boat speeds ranging from 15 to $40 \mathrm{~km} \mathrm{~h}^{-1}$ representing roughly a point every 4 to $11 \mathrm{~m}$, or two to seven measurements per pixel depending on sensor. The Amazon cruise data were collected at one minute intervals; the Mississippi and Columbia datasets were converted from $1 \mathrm{~s}$ intervals to 1 min median bins (Dall'Olmo et al., 2009) to match the GPS unit logging interval.

\subsection{In situ hyperspectral radiometry}

While biogeochemical data exists for rivers worldwide, parallel radiometric measurements over rivers are very rare. As such, in situ reflectance measurements were only possible during the Amazon field campaigns. In situ radiometric data were collected at stationary sampling sites during the Amazon cruises (Valerio et al., 2017) to provide a more quantitative assessment of atmospheric correction techniques.

Above-water hyperspectral radiometry data were collected using a portable hyperspectral radiometer FieldSpec ${ }^{\circledast}$ (ASD Inc.) which collects radiance $\left(L, \mu \mathrm{W} \mathrm{m}^{-2} \mathrm{sr}^{-1}\right)$ in the range of 350 to $1100 \mathrm{~nm}$ (bandwidth $1 \mathrm{~nm}$ ) and a field-of-view of $25^{\circ}$. The acquisition geometry followed (Mobley, 1999) recommendations to avoid shadows and sun and sky glint contamination. Total water-leaving radiance $\left(\mathrm{L}_{\mathrm{w}}\right)$, sky radiance $\left(\mathrm{L}_{\text {sky }}\right)$ and the radiance from a white Spectralon reference panel $\left(\mathrm{L}_{\mathrm{g}}\right)$ were consecutively measured 6 to 10 times in the same sequence using a fixed geometry, averaged and resampled to match satellite sensor bandwidths. During days with sparse clouds, the radiometer integration time was adjusted every time the sunlight condition changed and new measurements were made. The $\mathrm{L}_{\mathrm{g}}$ was used to estimate the downwelling irradiance $\left(\mathrm{E}_{\mathrm{d}}\right)$ (Eq. (1)):

$E_{d}(\lambda)=L_{g}(\lambda) f_{c} \pi$

where $f_{c}$ is a correction factor estimated in laboratory by the ratio of a standard Spectralon reference that remains in the laboratory to the
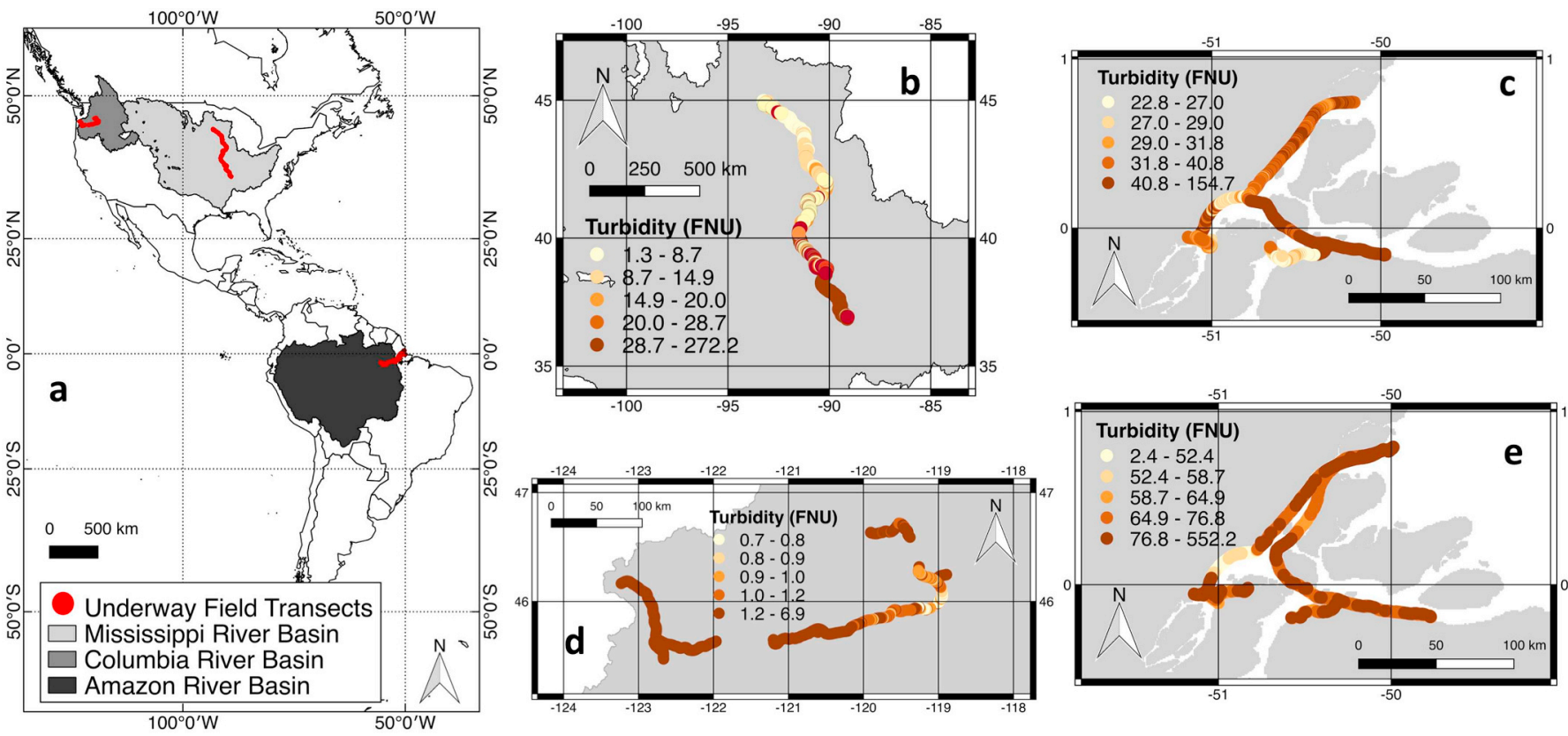

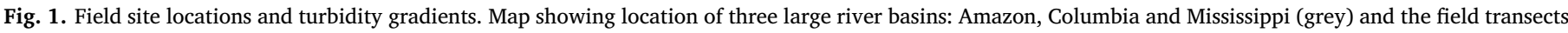

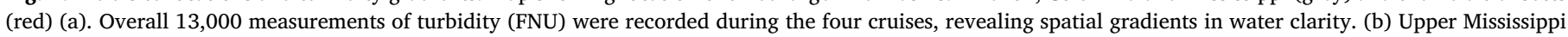

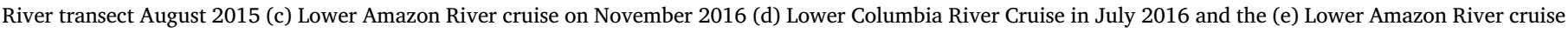
on April 2017. (For interpretation of the references to color in this figure legend, the reader is referred to the web version of this article.) 

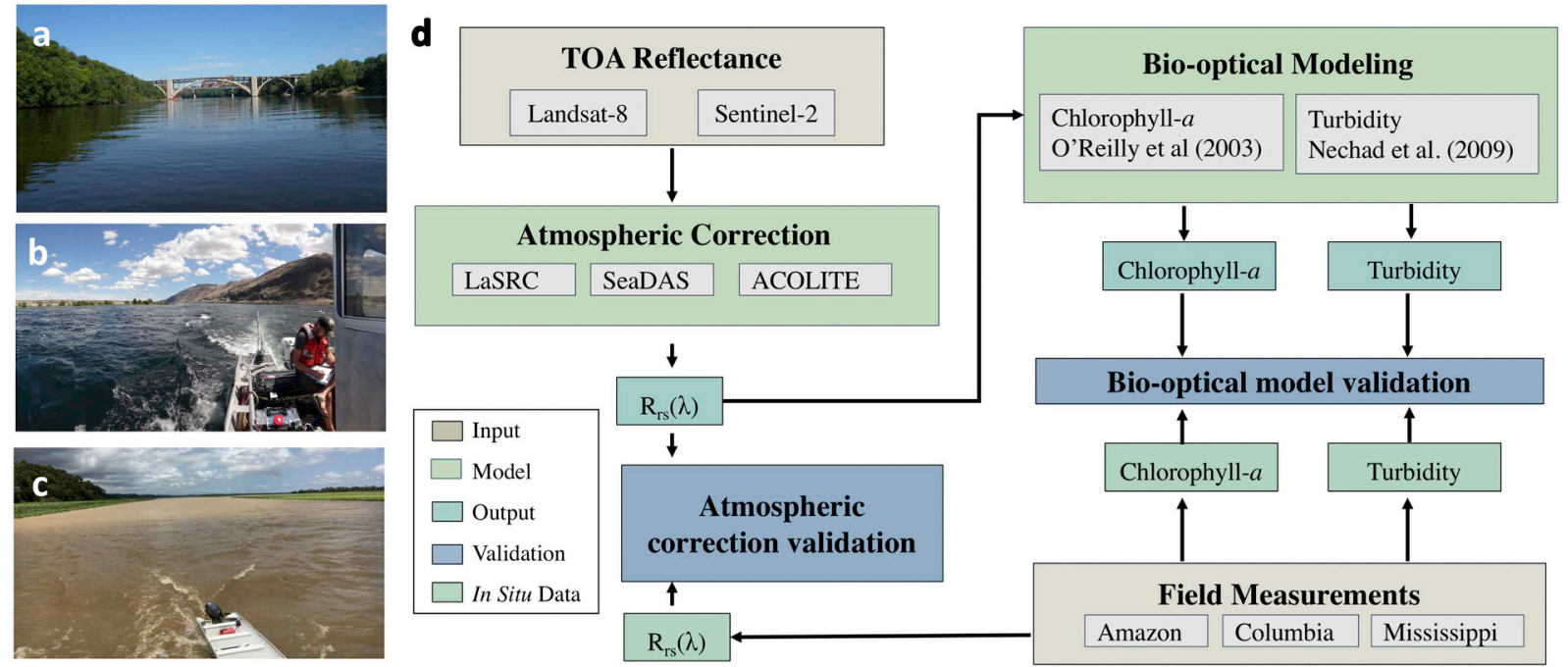

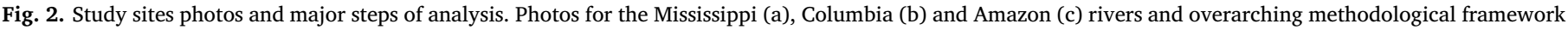
(d) showing major modeling steps, inputs and outputs.

Spectralon panel used at the fieldwork. The remote sensing reflectance $\left(R_{r s}\right)$ can be computed according to Eq. (2):

$R_{r s}=\frac{L_{w}}{E_{d}}=\frac{L_{u}-\rho_{\text {air-river }} * L_{s k y}}{E_{d}}$

where $L_{u}$ is the upwelling radiance that reaches the sensor and $\rho_{\text {air }- \text { river }}$ is a sun and sky glint correction coefficient at the air-sea interface. There are several methods in the literature to correct the optical signal from sky glint interference. The sun glint interference at this point should be minimum after redundant measurements made following viewing geometry proposed by Mobley (1999). The residual sun glint plus sky glint suggested by Ruddick et al. (2005) were corrected in the present study using the approach of Ruddick et al. (2006) for turbid to highly turbid waters. The $\rho_{\text {air-river }}$ is a function of wind and cloud cover (Eqs. (3a) and (3b)).

$\frac{L_{\text {sky }}(\lambda=750)}{E_{D}(\lambda=750)} \geq 0.05 \rightarrow \rho_{\text {air-river }}=0.0256$

or

$\frac{L_{\text {sky }}(\lambda=750)}{E_{D}(\lambda=750)}<0.05 \rightarrow \rho_{\text {air-river }}=0.0256+0.00039 \mathrm{~W}+0.000034 \mathrm{~W}^{2}$

where $\mathrm{W}$ is the wind $\left(\mathrm{m} \mathrm{s}^{-1}\right)$ measured concomitantly with the radiometric measurements. The residual glint and white offset correction was not performed for the spectra dataset. This correction usually is based on NIR spectrum (e.g. $\mathrm{R}_{\mathrm{rs}}$ (780) and $\mathrm{Rr}_{\mathrm{s}}$ (780), Ruddick et al., 2005) and assumes that its shape is largely determined by pure water absorption. In very turbid waters with high NIR reflectance like the Amazon River (Fig. 1d-e), the NIR variability is not linear (Wang et al., 2012; Goyens et al., 2013) After $R_{\mathrm{rs}}$ was calculated, the coefficient of variation ( $c v=$ (standard deviation/mean) 100$)$ of the $R_{r s}$ spectra replicates was computed for each station. Only the spectrum (considering the interval of $400-840 \mathrm{~nm}$ ) with $c v$ close or lower than $10 \%$ between the replicates was kept and averaged to get the final spectrum utilized in this study as a representative of $R_{r s}$ at each station.

\subsection{Satellite data}

L8, launched as a collaboration between the United States Geologic Survey (USGS) and National Aeronautics and Space Administration (NASA) on February 11, 2013, carries onboard the OLI pushbroom multispectral radiometer. While the 16 -day revisit period is similar to previous Landsat missions, L8's OLI sensor possesses several major enhancements including an additional band for coastal and aerosol applications $(443 \mathrm{~nm})$ and cirrus clouds $(1374 \mathrm{~nm})$. Designed to provide continuity with Landsat (Irons et al., 2012), the MultiSpectral Instrument (MSI) onboard ESA's S2 has a 5-day revisit time and 13 spectral bands in the visible to near infrared ( $443 \mathrm{~nm}-2190 \mathrm{~nm}$ ) (Drusch et al., 2012) and is also available through a variety of web providers including the USGS Earth Explorer site and Google Earth Engine (Gorelick et al., 2017). Compared to L8, the S2 sensor features a higher spatial resolution (10, 20 and $60 \mathrm{~m}$ ), shorter revisit period (5 days) and three additional bands in the near-infrared $(703,740$, and $783 \mathrm{~nm}$ ) region. Both instruments (Table S1) are quantized at 12-bits, and have much higher signal to noise ratios compared to previous Landsat missions and less frequent saturation over highly reflective targets (Pahlevan et al., 2014; Roy et al., 2014). While existing ocean color missions like the MOderate Resolution Imaging Spectroradiometer (MODIS) also have high radiometric resolution (16 bits) and more frequent revisit times (1-2 days), the finer spatial (10 to $60 \mathrm{~m}$ ) resolution of L8 and S2 is their major advantage over coarser ocean color sensors like Ocean and Land Color Instrument on board Sentinel-3 (300 m) and MODIS (250-1000 m).

Collection 1 Level 1 L8 and Level 1C S2 Top of the Atmosphere (TOA) data acquired during each cruise were identified by filtering to each region (Fig. 1) and cruise duration (Table 1) in Google Earth Engine (Gorelick et al., 2017). Over 140 total images were acquired over the rivers during the cruises. Of these, 121 were found unsuitable because of significant cloud cover ( $>90 \%$ ) or lack of overlap with the cruise transects in space or time (within $\leq 24 \mathrm{~h}$ ). The final 19 TOA images (Table 2) were downloaded from the USGS Earth Explorer (https://earthexplorer.usgs.gov/) in January 2018 and defined in their native World Geodetic System 84 (WGS84) datum and Universal Transverse Mercator (UTM) projection for use as inputs to the atmospheric correction routines. Note that the fusion of these two sensors into continuous time series is possible but outside the scope of this study.

\subsection{Atmospheric correction techniques}

In this study we test three atmospheric corrections using Level 1 TOA data as an input: the Landsat Surface Reflectance Code (LaSRC); the 12gen processor in SeaDAS; and a third method called ACOLITE (Vanhellemont and Ruddick, 2015). The first two are used by the USGS and NASA's OBPG to create land and ocean products. The last method is an open-source software processor developed at the Royal Belgian 
Table 2

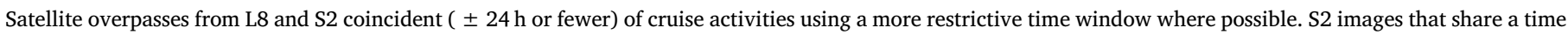

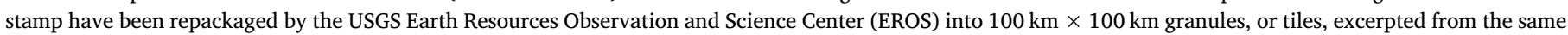
datatake.

\begin{tabular}{|c|c|c|c|c|c|}
\hline Sensor & River & Overpass date & Overpass time (UTC) & Time window $( \pm \text { hours })^{\mathrm{a}}$ & Path/row or tile \\
\hline \multirow[t]{4}{*}{ Landsat-8 } & Mississippi & $8 / 7 / 15$ & $16: 47: 13,16: 46: 50$ & 3 & 025/032, 025/031 \\
\hline & Columbia $^{\mathrm{a}}$ & $7 / 13 / 16$ & $18: 42: 58,18: 43: 22$ & 24 & 044/027, 044/028 \\
\hline & Amazon LW & $11 / 6 / 16$ & $13: 34: 59,13: 35: 23$ & 3 & $225 / 060,225 / 059$ \\
\hline & Amazon HW & $5 / 1 / 16$ & $13: 33: 56,13: 34: 20$ & 3 & $225 / 060,225 / 059$ \\
\hline \multirow[t]{4}{*}{ Sentinel-2 } & Mississippi $^{\mathrm{a}}$ & $8 / 7 / 15$ & $16: 42: 10$ & 12 & T15SYD, T16SBJ \\
\hline & Columbia $^{\mathrm{a}}$ & $7 / 14 / 16$ & 19:04:59, 19:01:37 & 12 & T10TGR, T10TGS, T11TLM, T10TFR, T11TLL \\
\hline & Amazon LW & $11 / 5 / 16$ & $13: 51: 10$ & 3 & T22MDE, T22MEE, T22NEF, T22MFE \\
\hline & & & & Total images $=$ & 19 \\
\hline
\end{tabular}

${ }^{\text {a }}$ Window of time in hours between closest coincident image acquisition and field measurements.

Institute of Natural Sciences (Vanhellemont and Ruddick, 2014, 2015, 2016). The overall differences between processors are described here and in Table S2.

The Landsat Surface Reflectance Code (LaSRC), was originally developed at NASA Goddard Flight Center for terrestrial applications. LaSRC uses the Second Simulation of the Satellite Signal in the Solar Spectrum (6SV) model and auxiliary data from MODIS climate grids to estimate aerosols, air temperature, water vapor (MOD09CMG), and ozone (MOD09CMA) (Vermote et al., 2016). LaSRC uses the coastal blue band (443-450 $\mathrm{nm}$ ), where aerosols typically have a strong signal, in combination with the red band for retrieving aerosols (Roy et al., 2014). The resulting USGS Collection 1 L8 reflectance product is widely available, including from the USGS Earth Explorer (Woodcock et al., 2008) and cloud providers such as Google Earth Engine, Amazon Web Services and Planet Labs. For this application, L8 and S2 images were processed in their native resolution (see Table S1) using LaSRC (v 3.5.5) at NASA Goddard Space Flight Center's Terrestrial Information Systems Laboratory.

NASA's OBPG has, in parallel, developed an approach specifically tuned for water and distributed in SeaDAS (version 7.0). SeaDAS's level 2 (12gen, v9.1.0) processor was used to produce remote sensing reflectance products for L8 (Franz et al., 2015) and S2 (Pahlevan et al., 2017a). To accommodate complex coastal waters, ocean color processing now incorporates an iterative, NIR-based correction (Bailey et al., 2010), which has been shown to reduce negative SeaWiFS retrievals in the blue $(412-490 \mathrm{~nm})$ by $40-100 \%$ for low to moderately turbid waters. For highly turbid waters (TSM $>35 \mathrm{mg} \mathrm{L}^{-1}$ ), however, NIR bands can saturate at calibrated TOA reflectance values $>2.0$ (unitless) (USGS, 2018). To address this we used NIR in combination with SWIR bands $(1 \mu \mathrm{m}<\lambda<3 \mu \mathrm{m})$, the latter of which appears dark even over very turbid water (Shi and Wang, 2009). Combining the NIR and SWIR bands has been shown to produce radiometrically stable $R_{\mathrm{rs}}$ estimates over turbid waters (Pahlevan et al., 2017c) more successfully than when either band is used in isolation (see Supplemental Text 2). The ratio of NIR to SWIR Rayleigh-corrected radiance reflectance was used, in combination with the relative humidity, to assign an aerosol type from a suite of models (Ahmad et al., 2010; Gordon and Wang, 1994). Results were then extracted using a spatially smoothed filter as described by Pahlevan et al. (2017a, 2017b) for L8 (30 m) and S2 (20 m) to minimize noise.

We also processed images using a third open-source software platform called ACOLITE (version 20170718.0). Designed specifically for atmospheric correction over marine and inland waters, ACOLITE supports both S2 and L8, and is publicly available for download (http:// odnature.naturalsciences.be/remsem/acolite-forum/) (Vanhellemont and Ruddick, 2014; Vanhellemont and Ruddick, 2015; Vanhellemont and Ruddick, 2016). In ACOLITE (version 20170718.0), TOA data were converted to water-leaving radiance reflectance $\left(\rho \mathrm{w}=\pi \times \mathrm{R}_{\mathrm{rs}}\right.$, dimensionless) in their native resolution by the removal of aerosols after radiometric calibration using sensor-specific gains (Pahlevan et al.,
2014). Aerosol type, specified as epsilon ( $\varepsilon$ ), was derived from userdesignated, scene-specific aerosol correction bands (NIR-SWIR in this case). Aerosol reflectance derived thus was then extrapolated to the visible bands and removed from the total signal. Here we chose a combined NIR-SWIR method with an $\varepsilon$ fixed per-scene to reduce pixellevel noise (Dogliotti et al., 2011). Clouds, land, glint and human infrastructure were masked using a SWIR $(\sim 1609 \mathrm{~nm})$ threshold suggested by Vanhellemont and Ruddick (2015) and Wang and Shi (2006) in which Rayleigh-corrected reflectances above $>0.0215$ (dimensionless) are considered to be non-water. Note that since the preparation of this manuscript, a new version of ACOLITE (Python 20180925.0) has been released that selects the atmospheric correction band from any part of the spectrum based on the resulting path radiance (Vanhellemont and Ruddick, 2018). This dark spectrum fitting method selects the "black pixel" in any wavelength, including the visible, and from whichever target, including building and tree shadows, that is the darkest. These changes are expected to alleviate some of the issues associated with using the SWIR band for atmospheric correction over water in the presence of adjacency effects.

\subsection{Water color algorithms}

In this study, standard satellite water color algorithms for inland waters were applied to atmospherically corrected data. Testing new approaches to bio-optical models in freshwater is an area of active research (see Supplementary Text 1 for discussion) outside the scope of this study. Here we selected standard, cross-platform approaches. Turbidity was estimated using a semi-empirical red band algorithm with L8's $655 \mathrm{~nm}$ band and S2's $665 \mathrm{~nm}$ band (Dogliotti et al., 2015; Nechad et al., 2009). Chl- $a$ was estimated using the widely-tested OC3 algorithm. A complete description is given in Supplementary Text 3. Intended for concentrations $>0.2 \mathrm{mg} \mathrm{m}^{-3}$, OC3 relates ratios of the maximum of the two blue bands $(443$ or $490 \mathrm{~nm}$ ) and green bands $(560 \mathrm{~nm})$ to Chl- $a$ with a fourth-order polynomial relationship (O'Reilly et al., 1998). While the red and NIR bands are in special cases used for estimating Chl- $a$ over very turbid waters (Sun et al., 2014; Le et al., 2011; Dall'Olmo et al., 2009) to avoid overestimating chlorophyll- $a$, we wanted to evaluate the performance of standard approaches over the dynamic range of our river sites as pre-existing products are likely to be of the greatest use to the water management and limnology communities. Atmospherically corrected satellite data from the three approaches were used to produce spatially continuous estimates of Chl- $a$ and turbidity over three river systems.

\subsection{Satellite data to in situ matchup considerations}

Outputs of the 19 images selected in this study (Table 2) from each of the three correction routines were then cloud-optimized, or tiled, for import into Google Cloud Storage (GCS). Satellite to in situ matchups were generated by importing all cloud-optimized imagery from GCS 
and field data points into Google Earth Engine (GEE) (Gorelick et al., 2017) for masking and sampling. To avoid the influence of clouds, all images were masked to clear, cloud-free pixels. L8 LaSRC Level 2 products allow users to specify both cloud and cloud shadow-free and water-only pixels using the pixel_qa band $(60 \mathrm{~m}$, where pixel_qa $=324$ ), thus masking any pixels flagged with medium or high confidence as land, cloud, or ice (Foga et al., 2017). S2's quality band $(\mathrm{QA60}, 60 \mathrm{~m}$ ) was used to mask clouds (where QA60 = 0). However, this band only indicates the presence or absence of clouds without the additional flags for water presence/absence available from the L8 L2 product so the dilated shoreline mask described below was used to isolate water pixels.

Shoreline effects from mixed pixels and breaking surf at the water's edge can contaminate dark targets and are a special concern for inland waters (Franz et al., 2015). To reduce this effect and minimize sub-pixel variability, field measurements collected within 3 pixels of the shoreline were discarded using a dilated shoreline mask. Shorelines were estimated using a land mask derived from the Surface Water Occurrence dataset (Pekel et al., 2016) where water occurrence $>90 \%$ is classified as water (0) and $<90 \%$ is classified as land (1). Each sampling point's distance to the nearest non-zero land pixel (i.e. the shoreline) was then calculated using a fast distance transform function and points close to shore ( $<3 \mathrm{~L} 8$ pixels) were excluded, resulting in a dataset representative of open water at a distance $>90 \mathrm{~m}$ from the shore. Data from both sensors was masked at $90 \mathrm{~m}$ for a conservative shoreline estimate.

Bailey and Werdell (2006) suggest match-ups between satellite and in situ data should ideally be restricted to field measurements collected within a 3-hour window of satellite overpass. However, other authors have demonstrated successful matchups using less restrictive windows of up to 3 days in lakes (Olmanson et al., 2008; Kloiber et al., 2002; Sriwongsitanon et al., 2011; Tebbs et al., 2013) under stable hydrologic and atmospheric conditions. For S2 and L8, local overpass times were around $11 \mathrm{a} . \mathrm{m}$. $\pm 0.5 \mathrm{~h}$, which allowed for a time difference of $<3 \mathrm{~h}$ in most cases unless otherwise noted. The difference in acquisition versus in situ time is noted for each cruise and sensor (Table 2).

To generate matchups, we sampled a $3 \times 3$ pixel box centered on each validation point. We required a majority of pixels ( $n \geq 5$ pixels) inside each $3 \times 3$ box to be retrieved to ensure sample size homogeneity within each box. Medians, arithmetic means, standard deviations and counts were calculated for each $3 \times 3$ pixel box for $\mathrm{R}_{\mathrm{rs}}$, Chl- $a$ and turbidity. A final filter included only points for which a valid reflectance was retrieved by all correction routines. This step ensured uncertainties were calculated using the same set of pixels from each technique.

To further constrain absolute accuracy, another set of filters as recommended by Bailey and Werdell (2006) was imposed for turbidity and Chl- $a$ (Fig. S1). As such, negative values and pixels outside of one standard deviation were excluded to reduce the influence of extreme outliers and mixed pixels. As a result of these quality control steps, only high-quality chlorophyll- $a$ and turbidity validation points were used, which restricted the final validation analysis to Columbia and Amazon High Water L8 acquisitions. The resulting data arrays were exported from GEE for statistical analysis and visualization using Python (version 2.7, Python Software Foundation, https://www.python.org/) and R (version 3.4.3, R Core Team, 2017, https://www.r-project.org/) in Jupyter Notebooks (Kluyver et al., 2016).

\subsection{Evaluation functions}

We evaluated algorithm performance following Bailey and Werdell (2006) to facilitate comparison to other studies. Statistics relating any satellite to in situ values included the median satellite to in situ ratio $\left(R_{t}\right)$, the semi-interquartile range (SIQR) and the root mean square difference (RMSD). These metric, though widely used, should be deployed cautiously and in combination with more robust metrics that allow for non-Gaussian distributions and large dynamic ranges (Seegers et al., 2018). Therefore, we also calculated the median absolute percent difference (MAPD). These metrics are defined as:

$\mathrm{Rt}=\operatorname{median}\left(\frac{X^{\text {mod }}}{X^{\text {obs }}}\right)$

$\mathrm{SIQR}=\frac{Q_{3}-Q_{1}}{2}$

$\operatorname{RMSD}(\Psi)=\sqrt{\frac{\sum_{i=1}^{n}\left(X^{m o d}-X^{o b s}\right)^{2}}{n}}$

$\operatorname{MAPD}=\operatorname{median}\left(100 * \frac{\left|X^{\text {mod }}-X^{o b s}\right|}{X^{\text {obs }}}\right)$

where $\mathrm{X}^{\text {obs }}$ and $\mathrm{X}^{\mathrm{mod}}$ are the in situ and satellite values for each sample point, $n$ is the number of samples, and the $Q_{1}$ and $Q_{3}$ are the 25th and 75th quartiles respectively. The SIQR demonstrates the spread or uncertainty associated with the satellite-retrieved values and the median ratio captures the overall bias. The Slope (S) and Intercept (I) were estimated by applying a reduced major axis (RMA) type II regression model (R package lmodel2 (Legendre, 2014)) to accommodate errors in both the field and satellite measurements (Ricker, 1973).

Slope $(\mathrm{S})=\frac{X^{\text {mod }}-1}{X^{\text {obs }}}$

Intercept (I) $=X^{\text {mod }}-S * X^{o b s}$

\section{Results and discussion}

\subsection{Underway data quality control}

The compiled dataset resulted in $>13,000$ measurements over 31 days and 3000 river kilometers. Measurements were collected over two different hydrologic conditions, Amazon low water (LW) and high water (HW) conditions in a tidally-influenced system and spanned a productivity gradient from the mesotrophic $\left(0.1<\mathrm{Chl}-a \leq 1 \mathrm{mg} \mathrm{m}^{-3}\right)$ Columbia to the eutrophic (Chl- $a>75 \mathrm{mg} \mathrm{m}^{-3}$ ) Mississippi (Franz et al., 2005). To our knowledge, this is the first use of high resolution, underway data for evaluating estimates of river turbidity and Chl- $a$ from L8. In situ values across these rivers revealed large gradients of turbidity (Figs. 1b-e, 2) at both small (e.g. mainstem versus tributary) and large (e.g. tropical versus temperate coniferous forest biomes) scales.

The dynamic range observed here (Fig. 3) falls within the range measured at 3400 marine stations $\left(0.012-72.12 \mathrm{mg} \mathrm{m}^{-3}\right)$ as reported in NASA's bio-Optical Marine Algorithm Data set (NOMAD) (Werdell and Bailey, 2005) as well as the range from the current largest Chl- $a$ ocean color validation set (0-100 $\mathrm{mg} \mathrm{m}^{-3}$ ) described by Seegers et al. (2018). Therefore, our in situ dataset for three major inland rivers falls within the envelope used to develop satellite-based ocean color products, providing evidence that rivers should fall within the dynamic range used to develop current ocean and coastal water techniques. For the rivers (Mississippi and Columbia) where higher-frequency measurements were binned, the median and standard deviation of the 1-minute bins was $44.7(4.7 \mu \mathrm{g} / \mathrm{L})$ and $2.19(0.37 \mu \mathrm{g} / \mathrm{L})$ for Chl- $a$ and was 26.3 FNU (2.09) FNU and 1.8 (0.12) FNU for the Mississippi and Columbia River respectively. The relatively low standard deviation suggests spatial stability throughout the main stem.

Of the 13,744 field validation points acquired across all cruises, 6405 spatially coincided with a satellite overpass. Restricting to a $24-$ hour window reduced the dataset size by $90 \%$ (Fig. 4 a). In order to ensure the same sample size for each correction technique, we included only pixels that passed all three corrections without masking (Fig. 4b). Pixels flagged under certain criteria are not processed and this varied by 

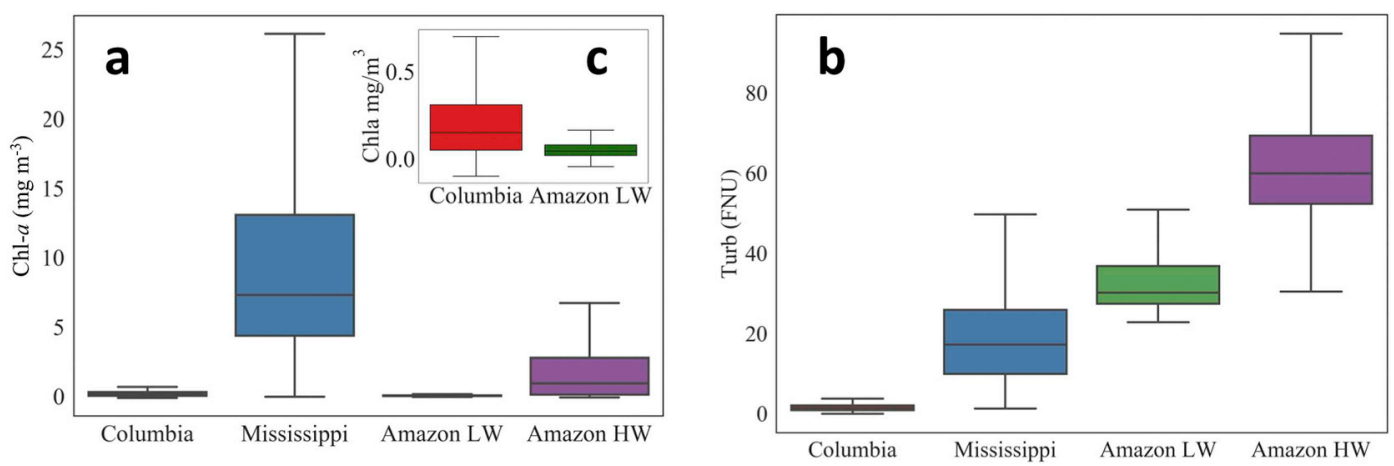

Fig. 3. Chlorophyll- $a$ (a) and turbidity (b) from each cruise. Low Chl-a systems (c) included the Columbia River and the Lower Amazon Low Water cruise.

routine.

For example, after masking with the QA band, LaSRC yielded 708 validation points, but ACOLITE and SeaDAS returned valid retrievals for $62 \%$ and $37 \%$ of those points respectively. This discrepancy is due to the fact that each routine uses a different set of flags, with SeaDAS (32 flags; Hooker et al., 2003) being more detailed in this case than ACOLITE (4 flags).

Less than $1 \%$ of samples were excluded due to low coverage ( $<5$ pixels) inside the sampled $3 \times 3$ pixel window (Fig. $4 c$ ). The shoreline mask only excluded $8 \%$ of pixels (Fig. 4d), likely because boat surveys generally maintained a steady course in deeper navigation channels and because of the previous coverage filter which reduced sampling window variability.

\subsection{Atmospheric correction}

Here we will first evaluate the number of failed retrievals, as indicated by negative $R_{r s}$ values, for each correction technique. We then discuss the differences between the land-based and aquatic correction techniques and quantitatively compare those results to field $R_{r s}$ measurements. Finally, we evaluate bias, based on differences from field observations, in the resulting chlorophyll-a and turbidity retrievals introduced by each correction.

\subsubsection{Negative $R_{r s}$ retrievals}

Analysis of L8 and S2 $\mathrm{R}_{\mathrm{rs}}$ observations over rivers are still relatively rare. Fig. 5 shows the range of possible $R_{r s}$ values in the green band across the entire river surface captured for the images (Table 2) before the quality control described in Section 3.6. This characterization shows the general performance of the atmospheric corrections before any uncertainties introduced by sampling the data at specific points. Negative retrievals can be an important diagnostic in determining the validity of $\mathrm{R}_{\mathrm{rs}}$. Across the dataset, $1 \%$ of $\mathrm{L} 8$ and $2 \%$ of S2 pixels showed $\mathrm{R}_{\mathrm{rs}} \leq 0 \mathrm{sr}^{-1}$ in the green bands (Fig. 5); more negative retrievals were observed in the blue bands ( $2 \%$ L8 and $10 \%$ S2), which are known to be sensitive to aerosol selection errors.

Negative retrievals can indicate a problem with atmospheric correction. Aquatic correction routines assume any SWIR reflectance to be from aerosols and subtract it as such from the rest of the spectra during the aerosol removal step. This assumption is based on the fact that even very shallow water absorbs longer wavelength light and thus should be dark $\left(\mathrm{R}_{\mathrm{rs}} \sim 0 \mathrm{sr}^{-1}\right)$ in the SWIR bands (Wang and Shi, 2007; Shi and Wang, 2009). However, SWIR signals from strong adjacency effects over inland water pixels have been widely documented in most (although not all, see Pahlevan et al., 2019) cases. While SWIR signals over water could be caused by emergent macrophytes (Dogliotti et al., 2018), nearby land pixels contributing SWIR signals are more likely the cause (Richter et al., 2006; Bulgarelli and Zibordi, 2018). For example, $96 \%$ of negative retrievals were from the Columbia (Fig. 5a, b), whose shorelines feature steep and bright cliffs. The Amazon LW and Mississippi images had fewer failed returns $(<1 \%$ ) (Fig. 5c, d, e, f, g) although adjacency effects are present in the TOA spectra of all rivers in this study.

The negative retrieval rate was twice as high for S2 (5\%) than for L8 $(2 \%)$ in the visible to near-infrared bands ( $\sim 400-865 \mathrm{~nm})$. In addition to adjacency effects, another contributing factor could be S2's higher spatial resolution. Smaller pixels resolve smaller wave features (Kay et al., 2009), amplifying the confounding effects of sun glitter. ACOLITE produced the most negative blue band retrievals (14\%) relative to SeaDAS (8\%) and LaSRC (6\%).
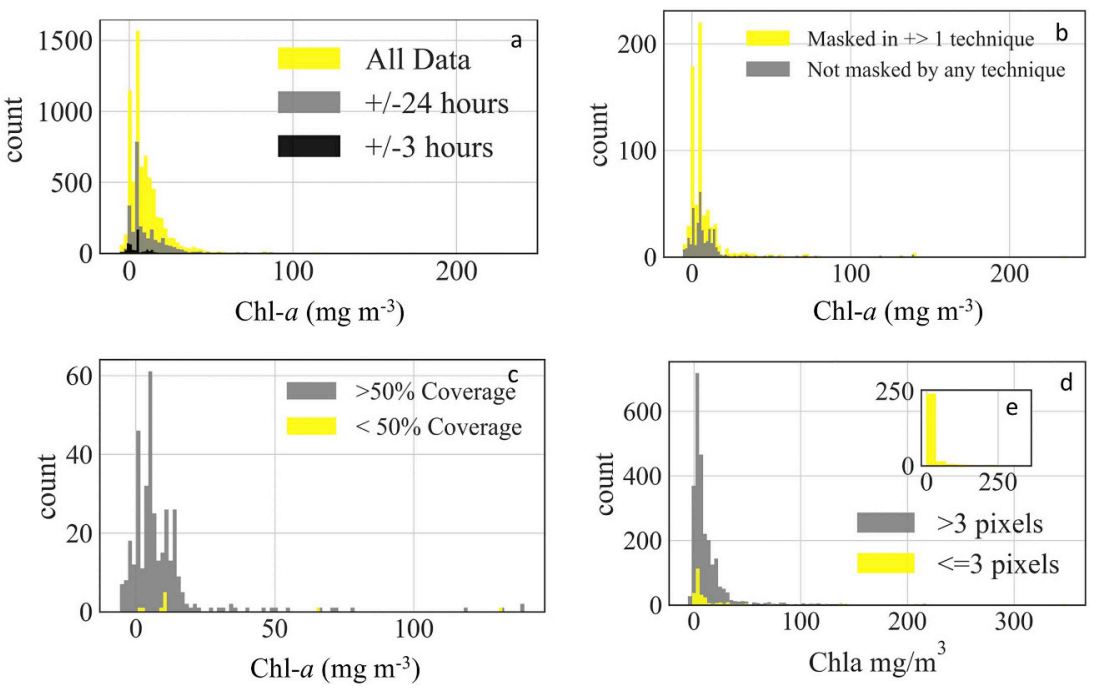

Fig. 4. Results from quality control procedure. The four-step method used (similar to Brewin et al., 2016; Werdell et al., 2013) resulting in the following: (a) Histogram showing the total number of points spatially coincident to an overpass (yellow) overlaid by those that spatiotemporally coincided within 24 (grey) and 3 (black) hours. (b) Histogram showing the points that escaped flagging across all routines (grey). (c) Histogram showing the distribution of all points remaining after (a) and (b) (grey) overlaid by the samples excluded because of $<50 \%$ coverage (i.e. $<5$ pixels) inside the $3 \times 3$ sampling window surrounding each validation point. (d) Histogram showing the distribution of points excluded (in yellow) because of their proximity ( $\leq 3$ pixels) to shore with an inset (e) showing just the distribution of the masked pixels. (For interpretation of the references to color in this figure legend, the reader is referred to the web version of this article.) 

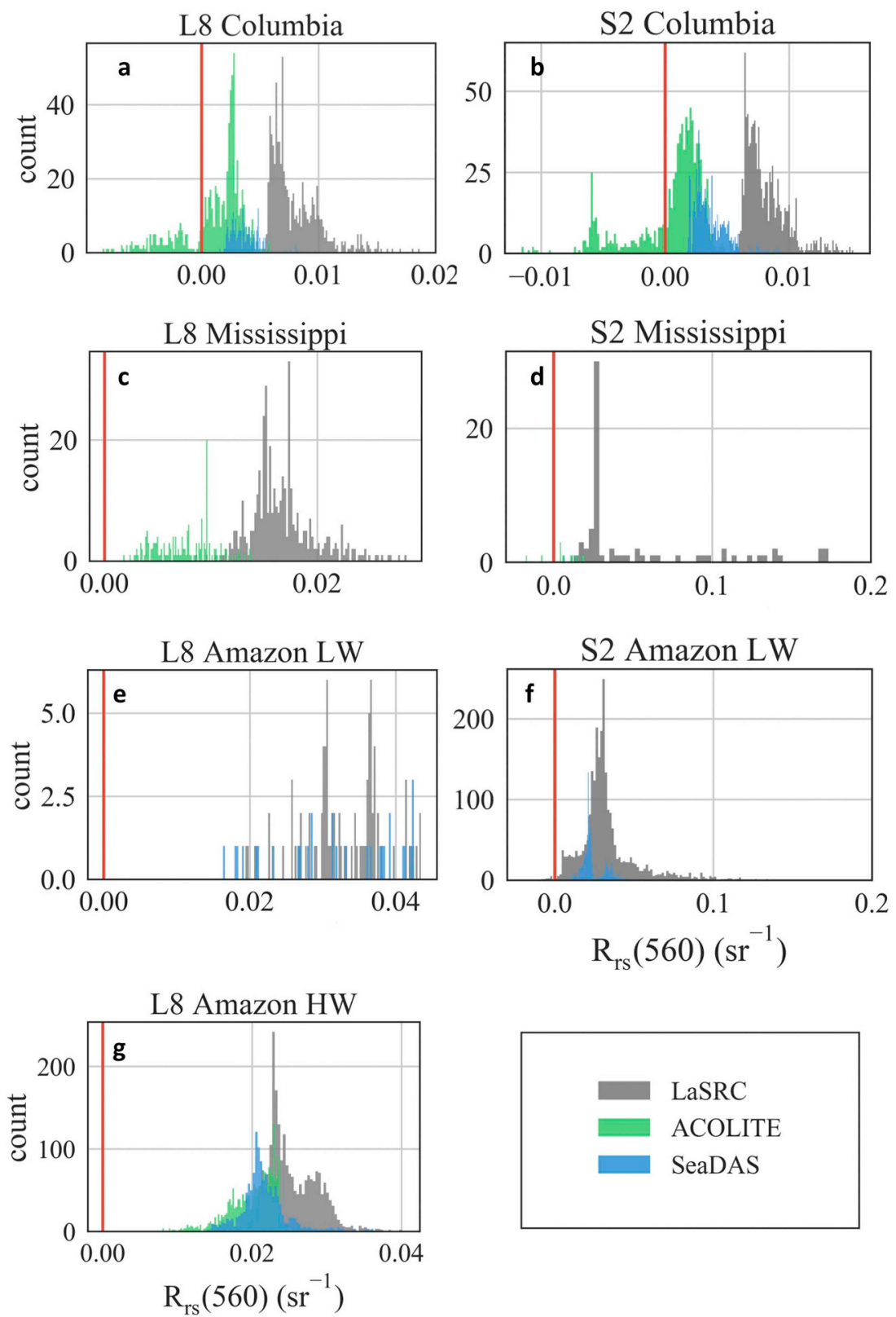

Fig. 5. Distributions of $S 2$ and L8-derived $\mathrm{R}_{\mathrm{rs}}\left(\mathrm{sr}^{-1}\right)$ shown for the green channel $(560 \mathrm{~nm})$ as estimated by the three atmospheric correction techniques for L8 ( $a, c, e, g$ ) and S2 (b, d, f). Distributions were derived from images listed in Table 2 before any quality control. As noted, L8 and S2 acquisitions are not comparable because they did not occur on the same day and there were no S2 matchups during Amazon HW. The red line indicates zero; points falling below are negative retrievals. Note the change in $\mathrm{x}$-axis between cruises reflective of the large gradient of water types surveyed here. (For interpretation of the references to color in this figure legend, the reader is referred to the web version of this article.)

\subsubsection{Land-based versus aquatic corrections}

After removal of failed retrievals, the resulting spectral plots derived from the scenes listed in Table 2 and processed as described in Section 3.6 show the top of the atmosphere (TOA) reflectance (unitless) and $\mathrm{R}_{\mathrm{rs}}$ $\left(\mathrm{sr}^{-1}\right.$ ) for the land (LaSRC) and aquatic (SeaDAS and ACOLITE) corrections for L8 (Fig. 6) and S2 (Fig. 7). The terrestrial technique produced higher $\mathrm{R}_{\mathrm{rs}}$ values than aquatic techniques by $36 \%$ MAPD, or $0.008 \mathrm{sr}^{-1}$ (Figs. 6, 7), across the L8 and S2 visible and near-infrared bands.

Clearer waters (Fig. 6e) showed larger departures between aquatic and terrestrial L8 techniques $\left(0.004 \mathrm{sr}^{-1}\right)$ in contrast to the turbid Amazon where differences narrowed to $0.001 \mathrm{sr}^{-1}$ (Fig. 6h) across bands. During the Amazon LW (Fig. 6g), aquatic and terrestrial methods overlapped, with notably high SeaDAS variability $\left(\mathrm{IQR}=0.01 \mathrm{sr}^{-1}\right)$ in the $430-512 \mathrm{~nm}$ range likely resulting from poor image quality. During the more turbid Amazon HW cruise, techniques converged in the NIR where differences between LaSRC and aquatic techniques closed to $0.0002 \mathrm{sr}^{-1}$.

Larger differences were observed in S2. Terrestrial and aquatic techniques diverged by $62 \%$, yielding differences in $\mathrm{R}_{\mathrm{rs}}$ an order of magnitude higher for S2 $\left(0.01 \mathrm{sr}^{-1}\right)$ than for L8 $\left(0.003 \mathrm{sr}^{-1}\right)$. By processor, LaSRC L8 $\mathrm{R}_{\mathrm{rs}}$ was on average 0.0027 and $0.0031 \mathrm{sr}^{-1}$ greater than ACOLITE and SeaDAS respectively. For S2 the difference from LaSRC was larger for ACOLITE $\left(0.02 \mathrm{sr}^{-1}\right)$ but not SeaDAS $\left(0.002 \mathrm{sr}^{-1}\right)$.

Differences in $\mathrm{R}_{\mathrm{rs}}$ result from differences in processor assumptions and correction bands. LaSRC estimates aerosols over land using the blue and red bands and extrapolates over water. This assumption would not be appropriate over open ocean waters distant from shore but could be reasonable across the shorter spatial scales relevant to inland waters. In contrast, aquatic techniques assume water absorbs NIR-SWIR strongly and therefore any SWIR reflectance is assigned to aerosols. However, as noted in Section 4.2.1, NIR remote sensing reflectance values $>0 \mathrm{sr}^{-1}$ at the water surface were observed in all rivers (Figs. 6a-d, 7a-c), likely stemming from adjacency effects or sun and sky glint (Bulgarelli and Zibordi, 2018). Thus, while the SWIR-based black pixel assumption might be reasonable even over turbid waters, it becomes problematic for systems with strong adjacency effects such as inland waters. For waterbodies with nearby and/or bright shorelines, NIR/SWIR 

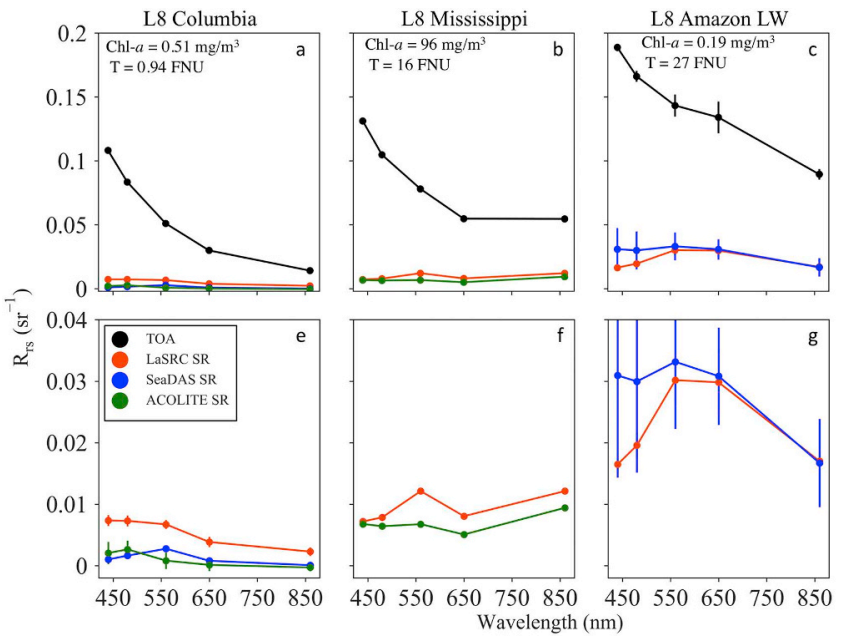

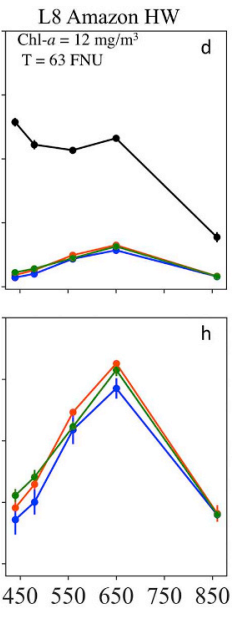

Fig. 6. $L 8$ TOA and $R_{r s}$. L8 $R_{r s}$ median spectra and interquartile range $(25 \%, 75 \%)$ by river contextualized against TOA values (unitless, top row) and subset to only $\mathrm{R}_{\mathrm{rs}}$ (bottom row). Median spectra for each river are derived from mosaicked campaign images (Table 2) after atmospheric correction (Section 3.4) and the quality control process described in Section 3.6 with $\mathrm{a} \pm 24 \mathrm{~h}$ filter to capture adequate samples, ( $n=180,3,9$ and 240) for the Columbia (a, d), the Mississippi (b, f), Amazon LW (c, g) and Amazon HW (d, h) respectively. In situ values collected on the same day and time as the overpass for mean chlorophyll-a (Chl- $a$ ) and turbidity (T) are shown in the top row for context. adjacency effects may be too strong for the NIR/SWIR atmospheric correction and consequently terrestrial or alternative methods may perform best.

However, considering the significant methodological differences in approaches, this convergence between aquatic and terrestrial techniques is encouraging and suggests choice of atmospheric correction may be less important when using L8 in highly reflective systems. The range of spectral shapes shown here also fall within that observed within an analysis conducted by Spyrakos et al. (2018) of over 250 inland and coastal water $R_{r s}$ spectra. The differences in spectra across optical gradients observed here are similar to those reported by Jackson et al. (2017) in a recent analysis of a large scale in situ $\mathrm{R}_{\mathrm{rs}}$ and Chl-a dataset (OC-CCI v2.0, Valente et al., 2016).

Users must be warned, however, that small differences in spectra can lead to large differences in the absolute accuracy of satellite-retrieved Chl- $a$ and turbidity values, especially if the biases are spectrallydependent. For example, band ratio models could be more impacted by differences in spectral shapes than magnitudes because of their dependence on relative contributions from each band. Here, processors resolved similar spectral shapes despite differences in magnitudes.

\subsubsection{Aquatic corrections}

While the terrestrial and aquatic methods produced spectra of differing magnitudes, the two aquatic corrections agree within $0.0006 \mathrm{sr}^{-1}$ across rivers and sensors. Differences were the smallest $\left(0.001 \mathrm{sr}^{-1}\right)$ in the blue and coastal blue bands for the Columbia (Fig. 6e) and for the green $\left(0.0005 \mathrm{sr}^{-1}\right)$ and NIR bands $\left(0.00004 \mathrm{sr}^{-1}\right)$ on the Amazon HW (Fig. 6h).

The difference between sensors was again pronounced, with a much larger gap between aquatic methods for S2 $\left(0.002 \mathrm{sr}^{-1}\right)$ than for L8 $\left(0.0009 \mathrm{sr}^{-1}\right)$. Zhang et al. (2018) reported S2 produced higher $\mathrm{R}_{\mathrm{rs}}$ values than L8 over land. These differences are likely related to environmental conditions or ground sampling resolution and not sensor specifications (Pahlevan et al., 2017a, 2017b). Despite difference between sensors, aquatic method disagreements are small relative to the differences between terrestrial and aquatic techniques. The similarity of these estimates likely stems from their shared use of the NIR-SWIR bands for atmospheric correction, in contrast to land-based methods which use different targets (dark dense vegetation), bands (blue and red) and assumptions.

Differences between aquatic methods showed spectral dependence. The S2 Mississippi spectra show a green peak $\left(0.02 \mathrm{sr}^{-1}\right)$ in the LaSRC spectra but not in ACOLITE (Fig. 7e). The aquatic corrections also vary
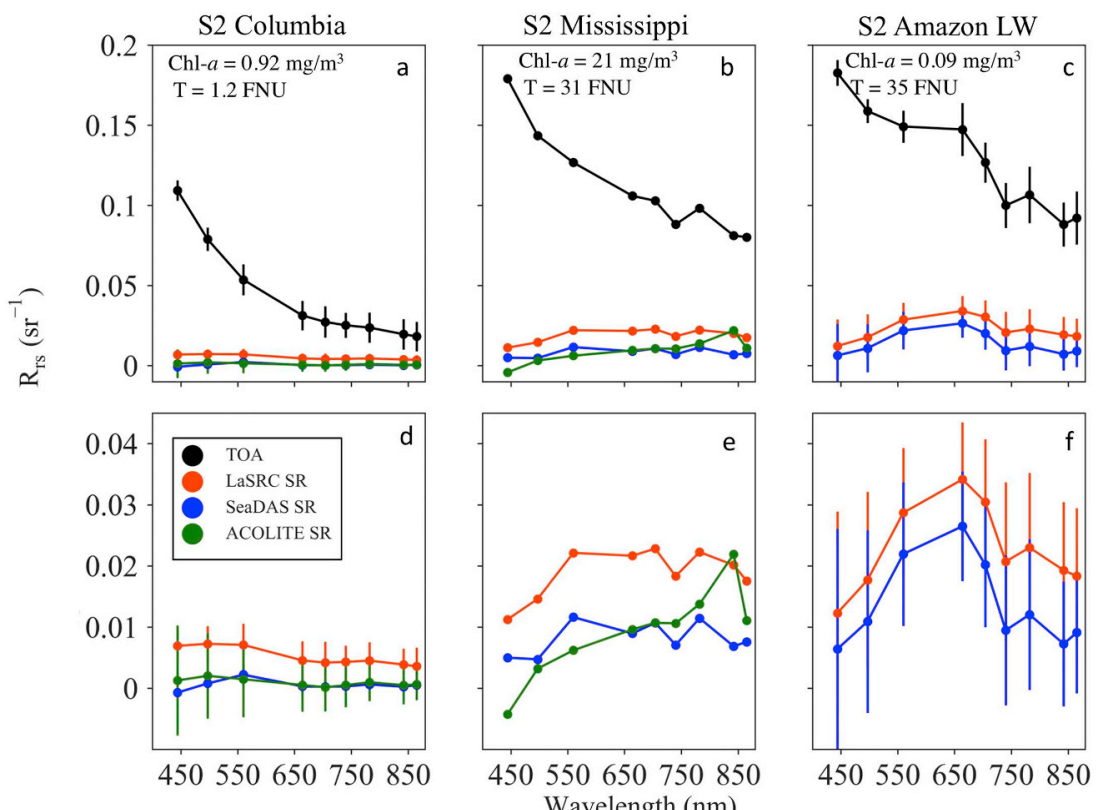

Fig. 7. S2 river TOA and remote sensing reflectance spectra. Median S2 $\mathrm{R}_{\mathrm{rs}}$ spectra and interquartile ranges (25\%, 75\%) extracted by river contextualized against TOA values (top row) and subset to only remote sensing reflectance (bottom row). Median spectra for each river are derived from mosaicked campaign images (Table 2) after atmospheric correction (Section 3.4) and the quality control process described in Section 3.6. Resulting median spectra from the quality controlled points ( $n=416,4$, and 1305) for the Columbia (a, d), the Mississippi (b, e), and Amazon LW (c, f) respectively. In situ values collected on the same day and time as the overpass for Chl- $a$ and turbidity are shown in the top rows. 

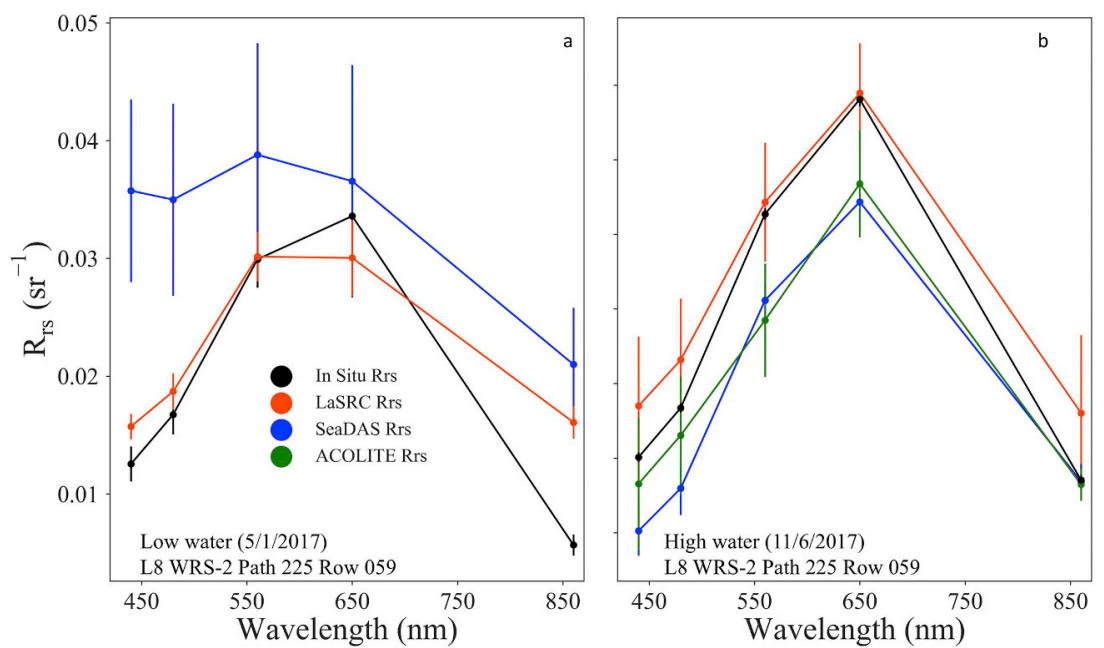

Fig. 8. Satellite $R_{\mathrm{rs}}$ shown with in situ $\mathrm{R}_{\mathrm{rs}}$. Median spectra and interquartile range $(25 \%, 75 \%)$ for resampled in situ radiometry in comparison to coincident $L 8 \mathrm{R}_{\mathrm{rs}}$ over the Amazon River during low water (a) and high water (b). Each overpass date and WRS-2 path/row are listed below the spectra. Hyperspectral in situ radiometry was collected at stationary stations on L8 overpass dates as listed on the plot and in Table 2. in L8's green band (560 nm) over the Columbia (Fig. 6e), where SeaDAS shows a peak $\left(0.003 \mathrm{sr}^{-1}\right)$ not observed in the ACOLITE spectra. A similar peak is observed in the S2 SeaDAS data $\left(0.002 \mathrm{sr}^{-1}\right)$ for the Columbia, despite only moderate in situ Chl- $a\left(0.5-1 \mathrm{mg} / \mathrm{m}^{-3}\right)$. Differences in NIR processing could drive these results. SeaDAS uses a modeled NIR value from iterative NIR processing while ACOLITE uses the NIR bands as given. While these spectral differences, as stated before, are likely to impact bio-optical models, the remote sensing reflectance estimated by these two aquatic techniques remain on the same order of magnitude.

\subsubsection{Validation of remote sensing reflectance}

Radiometric measurements for $\mathrm{R}_{\mathrm{rs}}$ validation were collected during Amazon high and low water coincident to L8 acquisitions (Table 2, Fig. 8). Unfortunately, no coincident S2 overpasses occurred. In situ measurements show peaks $\left(0.03-0.04 \mathrm{sr}^{-1}\right)$ in the red and near-infrared characteristic of highly scattering waters (Fig. 8) and strong absorption in the shorter wavelengths due to organic matter. These spectra show agreement with the shape and range $\left(0-0.02 \mathrm{sr}^{-1}\right)$ measured over turbid Amazon floodplain lakes (Martins et al., 2017) and coastal waters $\left(0-0.035 \mathrm{sr}^{-1}\right)$ influenced by the Amazon (Froidefond et al., 2002).

In comparisons to in situ radiometry (Fig. 8), LaSRC had the best agreement with an average MAPD across the spectrum of $17 \%$ (low water) and $4 \%$ (high water) with a RMSD as low as $0.001 \mathrm{sr}^{-1}$ during high water. This is approaching the $\pm 5 \%$ uncertainty benchmark often cited as a target for clear water radiances and bottom-of-the-atmosphere reflectance (Drusch et al., 2012; Bailey and Werdell, 2006; Hooker et al., 1992). LaSRC also showed less uncertainty than the aquatic techniques evidenced by a narrower SIQR (Table 3).

Aquatic techniques for the scenes analyzed here showed reasonable spectra with the exception of SeaDAS LW (Fig. 8a, b). Median ratios were $0.82<\mathrm{R}_{\mathrm{t}}<1.17$ with the SIQR indicating uncertainties of $<0.30$ except for SeaDAS (Table 3). No valid pixels coincident with

Table 3

Validation statistics for L8 atmospheric correction techniques over the Amazon river for the low (LW) and high water (HW) seasons for the OLI across the VNIR bands.

\begin{tabular}{lrlrrrr}
\hline Cruise & Correction & $\mathrm{R}_{\mathrm{t}}(\mathrm{SIQR})$ & MAPD (\%) & $\mathrm{RMSD}\left(\mathrm{sr}^{-1}\right)$ & Slope & $\mathrm{r}^{2}$ \\
\hline LW & SeaDAS & $1.79(1.35)$ & 79.39 & 0.01 & 0.46 & 0.52 \\
LW & LaSRC & $1.17(0.30)$ & 16.76 & 0.005 & 0.58 & 0.92 \\
HW & ACOLITE & $0.95(0.13)$ & 8.15 & 0.002 & 0.84 & 0.98 \\
HW & SeaDAS & $0.82(0.09)$ & 17.36 & 0.004 & 0.85 & 0.99 \\
HW & LaSRC & $0.96(0.05)$ & 3.87 & 0.001 & 0.95 & 1.00
\end{tabular}

field measurements were retrieved by ACOLITE during low water due to SWIR masking. During Amazon HW where all three corrections were available, ACOLITE MAPD $(\sim 8 \%)$ fell between LaSRC and SeaDAS. SeaDAS showed the least agreement with in situ measurements (MAPD of $\sim 17-79 \%)$. These results fall within the range reported by Wei et al. (2018) for L8 as corrected by both SeaDAS and ACOLITE using the NIR/ SWIR method over optically shallow and turbid waters, although ACOLITE shows higher performance here, possibly because this study used a fixed epsilon and a SWIR mask whereas Wei et al. (2018) used a per-pixel epsilon and did not specify use of a SWIR mask. Differences in these processing options could lead to higher MAPDs, especially because of the relatively low signal-to-noise ratios of the SWIR bands. RMSD ranged an order of magnitude (0.001-0.01 sr-1) but across both cruises LaSRC had a lower RMSD than either aquatic technique. For example, LaSRC showed an order of magnitude lower RMSD than SeaDAS during LW and 50\% and 75\% lower RMSD than ACOLITE and SeaDAS during HW.

During high water, in situ $\mathrm{R}_{\mathrm{rs}}$ was underestimated by the aquatic technique and overestimated by the terrestrial technique. During low water the bias varied spectrally. For example, satellite-retrieved $\mathrm{R}_{\mathrm{rs}}$ ' was higher than in situ data in the blue and NIR during Amazon LW (Fig. 8a). Adjacency effects could explain why the NIR signal observed from space is higher than in situ values (Bulgarelli and Zibordi, 2018). The presence of strong glint could also contribute additional NIR signal as observed by both field and satellite measurements.

Glint, a common issue for L8 and S2, could contribute additional scattered light to the satellite-observed signal and is currently not corrected for over turbid waters by most standard approaches. Glintremoval methods are predominantly developed for clear-water marine systems yet can profoundly influence $\mathrm{R}_{\mathrm{rs}}$ estimates (Gilerson et al., 2018). For water retrievals, glint corrections can cause up to $43 \%$ MAPD in $R_{r s}$, significantly impacting the resulting Chl- $a$ retrievals (Garaba et al., 2015). Little research exists on this topic for inland waters, although Overstreet and Legleiter (2017) evaluated glint corrections over shallow rivers and Brando et al. (2016) evaluated glint effects in underway river samples. Harmel et al. (2018) developed a glint correction that reduced bias between in situ and satellite $R_{r s}$ by $60 \%$. However, neither in situ nor satellite observations over turbid waters are currently glint corrected in standard approaches, representing a major limitation.

In the opposite case, negative bias in the aquatic techniques was observed in comparison to field measurements during the Amazon high water cruise. The underestimation could be due to overcorrection resulting from adjacency effects or other factors such as cloud shadows observed in some areas of the scene and absorbing aerosols. Absorbing aerosols are not accounted for in current aerosol models (Gordon and 
Wang, 1994) but are common in coastal zones. Absorbing aerosols are known to vary seasonally over the Amazon river mouth due to agricultural burning (Herman et al., 1997). These factors could all contribute to underestimation in the shorter wavelengths (440 and $480 \mathrm{~nm}$ ) as observed in the high water cruise (Fig. 8b). It is also important to note the bidirectional reflectance effects, which are not considered or corrected for in these routines, could also add to discrepancies between field and satellite observations.

While the terrestrial approach, LaSRC, showed the closest match with field spectra, radiometry was not available from the Columbia and Mississippi so the relative difference between satellite and in situ $\mathrm{R}_{\mathrm{rs}}$ over less turbid waters remains unknown. The larger gap between techniques over the Columbia discussed in Section 4.2.2 suggests that comparisons to field radiometry over clearer inland waters should be a research priority.

\subsection{Chlorophyll-a and turbidity}

We examined the sensitivity and absolute accuracy of satellite-retrieved Chl- $a$ and turbidity to atmospheric correction by comparing satellite and in situ measurements for cruises in which both aquatic techniques were available (see Fig. 8 for WRS Path/Row), which includes the L8 images acquired during the Columbia and Amazon HW cruises.

\subsubsection{Chlorophyll-a sensitivity to atmospheric correction}

Overall, SeaDAS-derived Chl- $a$ estimates were on average 2.7 times higher than ACOLITE and twice as high as field measurements (Fig. 9). For example, the $0.002 \mathrm{sr}^{-1}$ and $0.001 \mathrm{sr}^{-1}$ difference between SeaDAS and ACOLITE in the green and blue bands resulted in a difference of $6 \mathrm{mg} \mathrm{m}^{-3}$ Chl- $a$. Satellite-derived Chl- $a$ estimates from SeaDAS and LaSRC overestimated Chl- $a$ by $\sim 4.7 \mathrm{mg} \mathrm{m}^{-3}$ and $0.6 \mathrm{mg} \mathrm{m}^{-3}$, with median ratios exceeding 1 (Fig. 9, Table 4).

The absolute percent difference for SeaDAS (MAPD $=59 \%$ ) was higher than ACOLITE (MAPD $=30 \%$ ) and LaSRC (MAPD $=32 \%$ ), with SeaDAS-derived Chl- $a$ in some cases being overestimated by an order of magnitude in the mesotrophic waters of the Columbia River. ACOLITE products underestimated Chl- $a$ by $\sim 1.29 \mathrm{mg} \mathrm{m}^{-3}$ across both rivers but approximated field values more closely than SeaDAS; for the Columbia river ACOLITE and in situ Chl- $a$ distributions were not significantly different $(p$-value $=0.1$ ).

As all three estimates were made using the same bio-optical algorithm (OC3), the major factor controlling these differences is the reflectance product used as an input and the underlying atmospheric correction processors used to generate those reflectance products. The consistent overestimation by SeaDAS directly results from the differences in blue and green bands (Sections 4.2.2-4.2.3) observed in the reflectance spectra. In this case, higher remote sensing reflectance accuracies over the Amazon resulted in satellite-retrieved Chl- $a$ values close to field measurements.

The differences we observe here in these river systems are equivalent to those observed in other systems. For example, Dörnhöfer et al. (2018) also used a multisensory approach to estimate Chl- $a$ over German lakes resulting in RMSD's between 3.6 and $19.7 \mathrm{mg} \mathrm{m}^{-3}$ with errors varying between L8 and S2 sensors. Regardless of correction,
Table 4

Combined difference metrics $(n=320)$ comparing in situ to satellite-retrieved chlorophyll- $a$ (Chl- $a$ ) and turbidity (T) from both correction routines for data acquired within $24 \mathrm{~h}$.

\begin{tabular}{lrllll}
\hline Correction & MAPD (\%) & $\mathrm{R}_{\mathrm{t}}$ & RMSD & Parameter & Time difference \\
\hline ACO & 30 & 0.70 & 0.13 & Chl- $a$ & \pm 3 \\
SDS & 59 & 1.59 & 0.30 & Chl- $a$ & \pm 3 \\
LaSRC & 32 & 1.32 & 0.08 & Chl- $a$ & \pm 3 \\
ACO & 3 & 1.03 & 0.22 & $\mathrm{~T}$ & \pm 3 \\
SDS & 13 & 0.86 & 0.15 & $\mathrm{~T}$ & \pm 3 \\
LaSRC & 35 & 1.35 & 0.48 & $\mathrm{~T}$ & \pm 3 \\
\hline
\end{tabular}

differences from in situ measurements are lower than the factor of five commonly reported for empirically-based ocean Chl-a satellite retrievals (Dierssen and Karl, 2010) and fall below, with the exception of SeaDAS, the $40 \%$ error reported for the widely-used OC4v4 standard Chl- $a$ product (Laliberté et al., 2018), where errors were also largest in waters with $<0.5 \mathrm{mg} \mathrm{m}^{-3} \mathrm{Chl}-a$. It is important to note that the established OC3 coefficients were calibrated in reference to high performance liquid chromatography pigments (HPLC) whereas our underway validation data is derived from instantaneous fluorometers.

Where matchups were available at the exact moment of the satellite overpass, we conducted a sensitivity analysis to quantify changes in accuracies resulting from using more or less restrictive time windows. Boucher et al. (2016) showed using a time window of 2 instead of 5 days improved agreement between L8-retrieved and in situ Chl- $a$ values in northeastern lakes. In this study, using a time window of \pm 3 instead of $24 \mathrm{~h}$ reduced differences by $5 \%$ (ACOLITE) and $31 \%$ (SeaDAS) for Chl-a.

The blue green Chl- $a$ algorithms tested here are designed for systems in which Chl- $a$ is the dominant absorber. Consequently, in optically complex waters combinations of other components can result in a false Chl- $a$ signal. For example, in terrestrially-influenced waters, nonalgal particles and CDOM can also absorb in shorter wavelengths, changing the blue-green ratio and therefore leading to Chl- $a$ overestimation. Non-algal particles and CDOM can also contribute fluorescence, resulting in an overestimation of fluorometric Chl- $a$ (Roesler et al., 2017). For turbid systems like the Amazon, CDOM and suspended matter absorb strongly in shorter wavelengths, creating a green peak even in the absence of Chl-a. De Matos Valerio et al. (2018) reported CDOM absorption coefficients at $412 \mathrm{~nm}$ between 1.0 and $7.0 \mathrm{~m}^{-1}$ in non-turbid tributaries and the mainstem. The sensitivity of results to correction techniques, sensors and bio-optical model choice shown here indicates that satellite-retrieved Chl- $a$ values should be interpreted with great caution in optically complex waters, especially because the relatively wide L8 bands are less than optimal for detecting aquatic signals in optically complex environments.

\subsubsection{Turbidity sensitivity to atmospheric correction}

In contrast to Chl- $a$, for turbidity SeaDAS and ACOLITE show greater agreement with in situ measurements (Fig. 10). Differences between satellite-retrieved and measured values range from underestimates of $13 \mathrm{FNU}$ (SeaDAS) to overestimates of $12 \mathrm{FNU}$ (LaSRC). Over the Columbia ACOLITE and SeaDAS-derived turbidity were statistically similar to in situ measurements $(p$-value $=0.02)($ Fig. 10a).
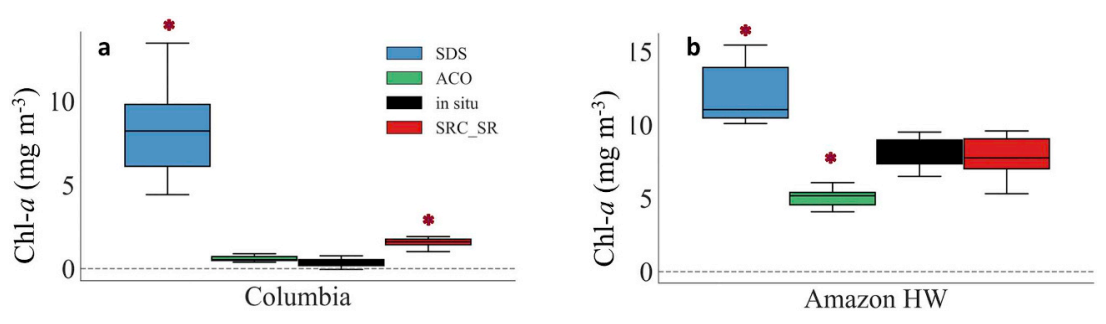

Fig. 9. Landsat-derived Chl- $a$ in comparison to in situ measurements. Given by river for the Columbia (a) and Amazon High Water (b) based on median of images for each river as listed in Table 2. Note the y-axis change. Red dots indicate significant difference from field measurements ( $p$-value $>$ 0.01). While TOA images are available for all the rivers, cloud masking and invalid pixel flagging result in no paired, valid pixels for the Mississippi and Amazon LW. (For interpretation of the references to color in this figure legend, the reader is referred to the web version of this article.) 

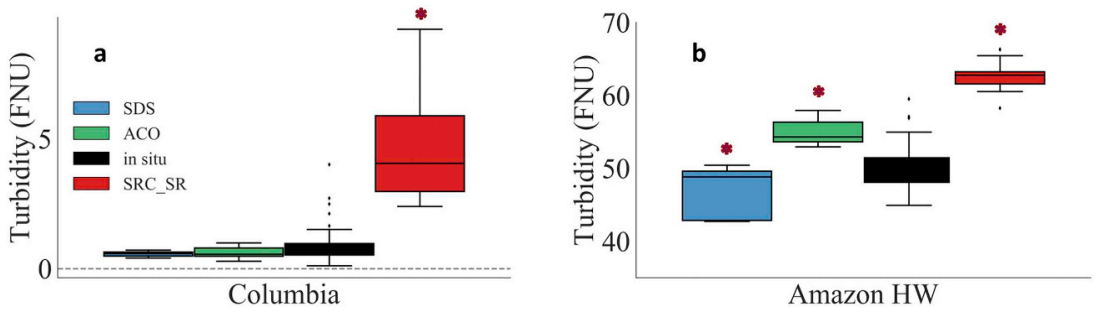

Fig. 10. Average Landsat-derived estimates of turbidity in comparison to in situ measurements. Scene ID's can be found in Table 2. The red dot indicates distributions that are statistically different from field measurements ( $p$-value $<0.01$ ). (For interpretation of the references to color in this figure legend, the reader is referred to the web version of this article.)
LaSRC had a larger mean absolute difference to in situ measurements (35\%) than ACOLITE (3\%) or SeaDAS (13\%) (Table 4) with larger differences observed at higher turbidities (Fig. 10b).

Over the Amazon, the range of satellite-retrieved turbidity (mean $=47-62 \mathrm{FNU}$ ) bracketed in situ values (mean $=50 \mathrm{FNU}$ ). Surprisingly, however, the $\mathrm{R}_{\mathrm{rs}}$ spectra with the lowest MAPD across the spectral for Amazon HW did not result in the most accurate turbidity estimate. LaSRC over-predicted turbidity across both rivers which follows from high red band peaks (Fig. 6). Turbidity derived from in situ radiometry $(636-673 \mathrm{~nm})$ was also overestimated (70 FNU) in reference to direct measurements (50 FNU). Thus both satellite and in situ reflectance values overestimate turbidity. This could result from additional contributions in the red from surface glint that could be addressed in future studies through the use of in-water radiometry or could also potentially be remedied by revisiting the turbidity algorithm calibration coefficients or using longer wavelengths (Dogliotti et al., 2015; Novoa et al., 2017).

The turbidity algorithm used here is directly comparable across platforms and thus differences can be mainly attributable to the atmospheric correction and performance of the bio-optical algorithm across a wide dynamic range. Inconsistencies in radiometric calibration between the two sensors are expected to contribute to $<6 \%$ of the total uncertainty (Pahlevan et al., 2019). The wide range of turbidities observed across inland waters in this study suggests a blended approach that utilizes different algorithms at different reflectance ranges such as used for Chl- $a$ (Hu et al., 2012) may be necessary to map turbidity across the entire dynamic range.

While turbidity is not a direct measure of a biogeochemical quantity (Boss et al., 2009), it's relative ease of measurement, including through crowd-sourced smartphone apps (Leeuw and Boss, 2018) and its usefulness for water quality monitoring (Nechad et al., 2009; Dogliotti et al., 2015) makes it a practical candidate for satellite remote sensing of aquatic optical conditions. These results show that while absolute accuracies of retrievals still require improvement, bio-optical algorithms are broadly able to discriminate between rivers, provided rivers span a large optical gradient.

\section{Summary \& further work}

This study highlights innovative underway field techniques used in combination with L8 and S2 satellite imagery to identify uncertainties in river remote sensing. We show that while all three corrections result in spectra on the same order of magnitude in most cases, the terrestrial atmospheric correction method produces a $36 \%\left(0.008 \mathrm{sr}^{-}\right)$greater $\mathrm{R}_{\mathrm{rs}}$ than aquatic techniques. The two aquatic approaches agree within $0.0006 \mathrm{sr}^{-1}$ but that varied by band, which in turn influences satellitederived Chl- $a$ and turbidity estimates. Where radiometric data were available, the standard land surface reflectance product had the best performance, achieving mean absolute differences as low as $4 \%$ relative to field measurements in turbid waters. When combined with bio-optical models, these $R_{r s}$ estimates can be useful for examining broad spatial gradients of Chl- $a$ and turbidity.

However, we strongly advise the cautious interpretation of these results because of uncertainties inherent to water color remote sensing that have yet to be resolved. Specifically, we advise future work on river remote sensing should occur in four major areas, especially as the application of remote sensing for water resource management applications is an increasing priority (McClain and Meister, 2012).

First, our findings show terrestrial correction techniques were able to resolve $\mathrm{R}_{\mathrm{rs}}$ over the Amazon River comparably to aquatic methods, likely because adjacency effects undermine SWIR-based aquatic correction approaches and despite the fact that terrestrial techniques do not correct for glint. To test this interaction, radiometric measurements over a range of river conditions is needed in addition to research examining adjacency effects. For example, De Keukelaere et al. (2018) show improved reflectance results using an L8/S2 atmospheric correction framework (iCOR) designed to work over inland waters with an explicit adjacency correction (Sterckx et al., 2015). More radiometric validation data, especially over oligotrophic systems, is a major research need. Such measurements are required to constrain estimates of $\mathrm{R}_{\mathrm{rs}}$ and to develop retrieval algorithms with sufficient absolute accuracy (Werdell et al., 2018).

Next, the assumptions and limitations of standard bio-optical retrieval methods need to be systematically re-evaluated in the context of rivers. While algorithms can resolve large differences in signals between systems, uncertainties in their quantitative, absolute accuracy must not be ignored (Pahlevan et al., 2016), especially because the wide bandwidths of the L8 and S2 sensors make them less than optimal for detecting aquatic signals in optically complex environments. A need exists to compare algorithm performance, especially across missions, to achieve product continuity (Mouw et al., 2015) and advance the field of inland water remote sensing. A first step is the development of sensoragnostic, open source bio-optical models that can take outputs from a range of correction processors. This will accelerate testing over a wider range of sensors and water types.

Global measurements of river inherent optical properties are needed to inform a process-based understanding of the relationship between river biogeochemistry, optical conditions and remote sensing reflectance. More geographically diverse radiometric and inherent optical property (e.g. particle backscattering coefficients, absorptions coefficients, diffuse attenuation) measurements are required. Fully understanding river productivity requires field measurements of parallel optical and biogeochemical properties. For example, although Chl- $a$ is generally low in the Amazon River main stem, evidence from dissolved oxygen stable isotopes suggest that primary production may still be occurring at up to $50 \%$ the rate of respiration (Gagne-Maynard et al., 2017). Establishing turbidity, CDOM and non-algal particle concentration thresholds for the use of blue/green chlorophyll-a algorithms could prevent the masking of chlorophyll-a by sediments and the overestimation of chlorophyll-a caused by the presence of non-algal particles and CDOM. Spyrakos et al. (2018) has made progress in classifying inland waters by their reflectance, which could be one approach to developing flexible bio-optical retrieval algorithms such as available for the open oceans. Future research is required to determine the dynamic range of river optical properties, their relationship to biogeochemistry, and their influence on remote sensing reflectance.

Finally, in addition to uncertainty from retrieval algorithms, a fourth major difficulty is establishing time benchmarks between field and satellite measurements in rivers, especially those influenced by short duration processes such as tides. We show constraining matchups 
to within $3 \mathrm{~h}$ can improve satellite-retrieved and in situ Chl- $a$ agreement by $>30 \%$, yet many large-scale sampling campaigns are still designed without consideration for overpass schedules. The mismatch in time scales between river processes (hours to days) and sensor return (5 to 16 days) times is a major limitation of current moderate to high resolution satellite missions. We have attempted to address that here by collecting underway data and using a strict data quality control process, but it is worth noting such efforts significantly reduce sample size (by $90 \%$ ) and consequent statistical power. National, regional and local water quality programs should coordinate sampling with satellite overpasses. Future sensors should combine moderate spatial resolutions $(<100 \mathrm{~m})$ with more frequent revisit periods (hours to days) (MullerKarger et al., 2018). Standardization of underway optical measurements for remote sensing through community protocols is in progress for the ocean (Werdell et al., 2013; Boss et al., 2018). Developing similar protocols for inland water surveys would improve comparability across studies and provide datasets of sufficient volume for inland water remote sensing calibration and validation.

\section{Acknowledgements}

This study evolved in part from early conversations at the Ocean Colors Remote Sensing Calibration and Validation course sponsored by the NASA Ocean Biology and Biogeochemistry Program. Funders include: Fundação de Amparo à Pesquisa do Estado de São Paulo (FAPESP) Grants 12/51187-0 and 2014/21564-2, NSF Ecosystem Studies 1256724, the U.S.G.S LandCarbon Program, Achievement Rewards for College Scientists, and the Integral Environmental Big Data Research Fund. NP was funded under NASA ROSES \#NNX16AI16G and the USGS Landsat Science Team Award \#140G0118C0011. Curt Mobley, Sean Bailey and Quinten Vanhellemont provided advice on atmospheric corrections. IFM and CSM made this work possible. Anna Simpson and UW's eScience Incubator program, including Amanda Tan, Rob Fatland and Don Seitung, provided early data science development and three anonymous reviewers benefited this work by providing thoughtful and constructive comments.

\section{Appendix A. Supplementary data}

Supplementary data to this article can be found online at https:// doi.org/10.1016/j.rse.2019.01.023.

\section{References}

Ahmad, Ziauddin, Franz, Bryan A., McClain, Charles R., Kwiatkowska, Ewa J., Werdell, Jeremy, Shettle, Eric P., Holben, Brent N., 2010. New aerosol models for the retrieval of aerosol optical thickness and normalized water-leaving radiances from the SeaWiFS and MODIS sensors over coastal regions and open oceans. Appl. Opt. 49 (29), 5545-5560 Optical Society of America.

Aiken, James, Hooker, Stanford, 1997. The Atlantic Meridional Transect: Spatially Extensive Calibration and Validation of Optical Properties and Remotely Sensed Measurements of Ocean Colour.

Bailey, Sean W., Werdell, P. Jeremy, 2006. A multi-sensor approach for the on-orbit validation of ocean color satellite data products. Remote Sens. Environ. 102 (1-2), 12-23. https://doi.org/10.1016/j.rse.2006.01.015.

Bailey, Sean W., Franz, Bryan A., Jeremy Werdell, P., 2010. Estimation of near-infrared water-leaving reflectance for satellite ocean color data processing. Opt. Express 18.7, $7521-7527$.

Barnes, Brian B., Hu, Chuanmin, 2016. Dependence of satellite ocean color data products on viewing angles: a comparison between SeaWiFS, MODIS, and VIIRS. Remote Sens. Environ. 175 (March), 120-129. https://doi.org/10.1016/j.rse.2015.12.048.

Boss, Emmanuel, Taylor, Lisa, Gilbert, Sherryl, Gundersen, Kjell, Hawley, Nathan, Janzen, Carol, Johengen, Tom, Purcell, Heidi, Robertson, Charles, Schar, Daniel W.H., 2009. Comparison of inherent optical properties as a surrogate for particulate matter concentration in coastal waters. Limnol. Oceanogr. Methods 7 (11), 803-810 Wiley Online Library.

Boss, E., Ackleson, S., Balch, B., Chase, A., Dall'Olmo, G., Freeman, S., Haëntjens, J.N., et al., 2018. Inherent Optical Property Measurements and Protocols: Best Practices for the Collection and Processing of Ship-based Underway Flow-through Optical Data. http://ioccg.org/wp-content/uploads/2017/11/inline_report_15nov2017.pdf.

Boucher, J.M., Weathers, K.C., Norouzi, H., Prakash, S., Saberi, S.J., 2016. Assessing the effectiveness of Landsat 8 chlorophyll-a retrieval algorithms for regional freshwater management. In: AGU Fall Meeting Abstracts.

Brando, Vittorio E., Lovell, Jenny L., King, Edward A., Boadle, David, Scott, Roger, Schroeder, Thomas, 2016. The potential of autonomous ship-borne hyperspectral radiometers for the validation of ocean color radiometry data. Remote Sens. 8 (2), 150 Multidisciplinary Digital Publishing Institute.

Brewin, Robert J.W., Dall'Olmo, Giorgio, Pardo, Silvia, van Dongen-Vogels, Virginie, Boss, Emmanuel S., 2016. Underway spectrophotometry along the Atlantic meridional transect reveals high performance in satellite chlorophyll retrievals. Remote Sens. Environ. 183, 82-97. https://doi.org/10.1016/j.rse.2016.05.005.

Bulgarelli, Barbara, Zibordi, Giuseppe, 2018. On the detectability of adjacency effects in ocean color remote sensing of mid-latitude coastal environments by SeaWiFS, MODIS-A, MERIS, OLCI, OLI and MSI. Remote Sens. Environ. 209, 423-438 Elsevier.

Carr, Mary-Elena, Friedrichs, Marjorie A.M., Schmeltz, Marjorie, Aita, Maki Noguchi, Antoine, David, Arrigo, Kevin R., Asanuma, Ichio, Aumont, Olivier, Barber, Richard, Behrenfeld, Michael, 2006. A comparison of global estimates of marine primary production from ocean color. Deep Sea Res. Part II: Top. Stud. Oceanogr. 53 (5), 741-770 Elsevier.

Crawford, John T., Loken, Luke C., Stanley, Emily H., Stets, Edward G., Dornblaser, Mark M., Striegl, Robert G., 2016. Basin scale controls on $\mathrm{CO}_{2}$ and $\mathrm{CH}_{4}$ emissions from the Upper Mississippi River. Geophys. Res. Lett. https://doi.org/10.1002/ 2015GL067599. n/a-n/a.

Crawford, John T., Butman, David E., Loken, Luke C., Stadler, Philipp, Kuhn, Catherine, Striegl, Robert G., 2017. Spatial variability of $\mathrm{CO}_{2}$ concentrations and biogeochemistry in the Lower Columbia River. Inland Waters 7 (4), 417-427. https://doi.org/10. 1080/20442041.2017.1366487. Taylor \& Francis.

Dall'Olmo, G., Westberry, T.K., Behrenfeld, M.J., Boss, Emmanuel, Slade, W.H., 2009. Significant contribution of large particles to optical backscattering in the open ocean. Biogeosciences 6 (6), 947-967 Copernicus GmbH.

de Matos Valerio, A., et al., 2018. Using CDOM optical properties for estimating DOC concentrations and pCO 2 in the Lower Amazon River. Opt. Express 26.14, A657-A677.

Dierssen, Heidi M., 2010. Perspectives on empirical approaches for ocean color remote sensing of chlorophyll in a changing climate. Proc. Natl. Acad. Sci. 107 (40), 17073-17078 National Acad Sciences.

Dierssen, Heidi M., Karl, David M., 2010. Perspectives on empirical approaches for ocean color remote sensing of chlorophyll in a changing climate. Proc. Natl. Acad. Sci. 107 (40), 17073-17078. https://doi.org/10.1073/pnas.0913800107.

Dogliotti, A.I., Ruddick, K., Nechad, B., Lasta, C., 2011. Improving water reflectance retrieval from MODIS imagery in the highly turbid waters of La Plata River. In: Proceedings of the VI International Conference Current Problems in Optics of Natural Waters (ONW'2011), St. Petersburg, Russia, pp. 6-9.

Dogliotti, Ana Inés, Ruddick, K.G., Nechad, B., Doxaran, D., Knaeps, E., 2015. A single algorithm to retrieve turbidity from remotely-sensed data in all coastal and estuarine waters. Remote Sens. Environ. 156, 157-168 Elsevier.

Dogliotti, Ana, Gossn, Juan, Vanhellemont, Quinten, Ruddick, Kevin, 2018. Detecting and quantifying a massive invasion of floating aquatic plants in the Río de La Plata turbid waters using high spatial resolution ocean color imagery. Remote Sens. 10 (7), 1140 Multidisciplinary Digital Publishing Institute.

Dörnhöfer, Katja, Oppelt, Natascha, 2016. Remote sensing for lake research and monitoring-recent advances. Ecol. Indic. 64, 105-122 Elsevier.

Dörnhöfer, Katja, Klinger, Philip, Heege, Thomas, Oppelt, Natascha, 2018. Multi-sensor satellite and in situ monitoring of phytoplankton development in a eutrophic-mesotrophic lake. Sci. Total Environ. 612, 1200-1214 Elsevier.

Doxani, Georgia, Vermote, Eric, Roger, Jean-Claude, Gascon, Ferran, Adriaensen, Stefan, Frantz, David, Hagolle, Olivier, Hollstein, André, Kirches, Grit, Li, Fuqin, 2018. Atmospheric correction inter-comparison exercise. Remote Sens. 10 (2), 352 Multidisciplinary Digital Publishing Institute.

Drusch, M., Del Bello, U., Carlier, S., Colin, O., Fernandez, V., Gascon, F., Hoersch, B., et al., 2012. Sentinel-2: ESA's optical high-resolution mission for GMES operational services. Remote Sens. Environ. 120 (May), 25-36. https://doi.org/10.1016/j.rse. 2011.11.026.

Fay, Amanda R., McKinley, Galen A., 2017. Correlations of surface ocean $\mathrm{PCO}_{2}$ to satellite chlorophyll on monthly to interannual timescales. Glob. Biogeochem. Cycles 31 (3), 436-455. https://doi.org/10.1002/2016GB005563.

Fichot, Cédric G., Downing, Bryan D., Bergamaschi, Brian A., Windham-Myers, Lisamarie, Marvin-DiPasquale, Mark, Thompson, David R., Gierach, Michelle M., 2015. highresolution remote sensing of water quality in the san francisco bay-delta estuary. Environ. Sci. Technol. 50 (2), 573-583 ACS Publications.

Foga, Steve, Scaramuzza, Pat L., Guo, Song, Zhu, Zhe, Dilley, Ronald D., Beckmann, Tim, Schmidt, Gail L., Dwyer, John L., Hughes, M. Joseph, Laue, Brady, 2017. Cloud detection algorithm comparison and validation for operational Landsat data products. Remote Sens. Environ. 194, 379-390 Elsevier.

Franz, Bryan A., Jeremy Werdell, P., Meister, Gerhard, Bailey, Sean W., Eplee, Robert E., Feldman, Gene C., Kwiatkowska, Ewa J., McClain, Charles R., Patt, Frederick S., Thomas, Donna, 2005. The continuity of ocean color measurements from SeaWiFS to MODIS. In: Earth Observing Systems X. International Society for Optics and Photonics 5882:58820W.

Franz, Bryan A., Bailey, Sean W., Kuring, Norman, Werdell, P. Jeremy, 2015. Ocean Color Measurements With the Operational Land Imager on Landsat-8: Implementation and Evaluation in SeaDAS. https://doi.org/10.1117/1.JRS.9.096070.

Froidefond, Jean-Marie, Gardel, Laure, Guiral, Daniel, Parra, Mario, Ternon, JeanFrançois, 2002. spectral remote sensing reflectances of coastal waters in French Guiana under the Amazon influence. Remote Sens. Environ. 80 (2), 225-232 Elsevier.

Gagne-Maynard, William C., Ward, Nicholas D., Keil, Richard G., Sawakuchi, Henrique O., Da Cunha, Alan C., Neu, Vania, Brito, Daimio C., Da Silva Less, Diani F., Diniz, Joel E.M., Valerio, Aline De Matos, 2017. Evaluation of primary production in the 
lower Amazon River based on a dissolved oxygen stable isotopic mass balance. Front. Mar. Sci. 4, 26 Frontiers.

Garaba, Shungudzemwoyo P., Voß, Daniela, Wollschläger, Jochen, Zielinski, Oliver, 2015. Modern approaches to shipborne ocean color remote sensing. Appl. Opt. 54 (12), 3602-3612 Optical Society of America.

Gilerson, Alexander, Carrizo, Carlos, Foster, Robert, Harmel, Tristan, 2018. Variability of the reflectance coefficient of skylight from the ocean surface and its implications to ocean color. Opt. Express 26 (8), 9615-9633 Optical Society of America.

Gordon, Howard R., 1978. Removal of atmospheric effects from satellite imagery of the oceans. Appl. Opt. 17 (10), 1631-1636 Optical Society of America.

Gordon, Howard R., Wang, Menghua, 1994. Retrieval of water-leaving radiance and aerosol optical thickness over the oceans with SeaWiFS: a preliminary algorithm. Appl. Opt. 33 (3), 443-452 Optical Society of America.

Gorelick, Noel, Hancher, Matt, Dixon, Mike, Ilyushchenko, Simon, Thau, David, Moore, Rebecca, 2017. Google Earth Engine: Planetary-scale Geospatial Analysis for Everyone. https://doi.org/10.1016/j.rse.2017.06.031.

Goyens, Clémence, Jamet, Cédric, Schroeder, T., 2013. Evaluation of four atmospheric correction algorithms for MODIS-aqua images over contrasted coastal waters. Remote Sens. Environ. 131, 63-75 Elsevier.

Griffin, C.G., et al., 2018. Quantifying CDOM and DOC in major Arctic rivers during icefree conditions using Landsat TM and ETM + data. Remote Sens. Environ. 209, 395-409.

Hadjimitsis, Diofantos G., Clayton, C.R.I., Hope, V.S., 2004. An assessment of the effec tiveness of atmospheric correction algorithms through the remote sensing of some reservoirs. Int. J. Remote Sens. 25 (18), 3651-3674 Taylor \& Francis.

Harmel, Tristan, Chami, Malik, Tormos, Thierry, Reynaud, Nathalie, Danis, Pierre-Alain, 2018. Sunglint correction of the Multi-Spectral Instrument (MSI)-SENTINEL-2 imagery over inland and sea waters from SWIR bands. Remote Sens. Environ. 204, 308-321 Elsevier.

Herman, J.R., Bhartia, P.K., Or, Torres, Hsu, C., Seftor, C., Celarier, E., 1997. Global distribution of UV-absorbing aerosols from Nimbus 7/TOMS data. J. Geophys. Res. Atmos. 102 (D14), 16911-16922 Wiley Online Library.

Hestir, Erin Lee, Brando, Vittorio E., Bresciani, Mariano, Giardino, Claudia, Matta, Erica, Villa, Paolo, Dekker, Arnold G., 2015. Measuring freshwater aquatic ecosystems: the need for a hyperspectral global mapping satellite mission. Remote Sens. Environ. 167, 181-195. https://doi.org/10.1016/j.rse.2015.05.023.

Hooker, Stanford B., Firestone, Elaine R., Esaias, Wayne E., Feldman, Gene C., Gregg, Watson W., Mcclain, Charles R., 1992. SeaWiFS Technical Report Series. Volume 1: An Overview of SeaWiFS and Ocean Color.

Hooker, Stanford, Firestone, Elaine R., Patt, Frederick S., Barnes, Robert A., Eplee Jr, Robert E., Franz, Bryan A., Robinson, Wayne D., Feldman, Gene Carl, Bailey, Sean W., 2003. Algorithm Updates for the Fourth SeaWiFS Data Reprocessing.

Hu, Chuanmin, Lee, Zhongping, Franz, Bryan, 2012. Chlorophyll aalgorithms for oligotrophic oceans: a novel approach based on three-band reflectance difference. J. Geophys. Res. Oceans 117 (C1) (Wiley Online Library).

Irons, James R., Dwyer, John L., Barsi, Julia A., 2012. The next Landsat satellite: the Landsat data continuity mission. Remote Sens. Environ. 122, 11-21 Elsevier.

Jackson, Thomas, Sathyendranath, Shubha, Mélin, Frédéric, 2017. An improved optical classification scheme for the ocean colour essential climate variable and its applications. Remote Sens. Environ. 203, 152-161. https://doi.org/10.1016/j.rse.2017. 03.036.

Kay, Susan, Hedley, John D., Lavender, Samantha, 2009. Sun glint correction of high and low spatial resolution images of aquatic scenes: a review of methods for visible and near-infrared wavelengths. Remote Sens. 1 (4), 697-730 Molecular Diversity Preservation International.

De Keukelaere, L., Sterckx, S., Adriaensen, S., Knaeps, E., Reusen, I., Giardino, C., Bresciani, M., et al., 2018. Atmospheric correction of Landsat-8/OLI and Sentinel-2/ MSI data using ICOR algorithm: validation for coastal and inland waters. Eur. J. Remote Sens. 51 (1), 525-542. https://doi.org/10.1080/22797254.2018.1457937. Taylor \& Francis.

Kloiber, Steven M., Brezonik, Patrick L., Olmanson, Leif G., Bauer, Marvin E., 2002. A procedure for regional lake water clarity assessment using Landsat multispectral data. Remote Sens. Environ. 82 (1), 38-47 Elsevier.

Kluyver, Thomas, Ragan-Kelley, Benjamin, Pérez, Fernando, Granger, Brian E., Bussonnier, Matthias, Frederic, Jonathan, Kelley, Kyle, Hamrick, Jessica B., Grout, Jason, Corlay, Sylvain, 2016. Jupyter Notebooks-A Publishing Format for Reproducible Computational Workflows. ELPUB, pp. 87-90.

Laliberté, Julien, Larouche, Pierre, Devred, Emmanuel, Craig, Susanne, 2018. Chlorophyll-a concentration retrieval in the optically complex waters of the St. Lawrence estuary and gulf using principal component analysis. Remote Sens. 10 (2), 265 Multidisciplinary Digital Publishing Institute.

Le, Chengfeng, Li, Yunmei, Zha, Yong, Sun, Deyong, Huang, Changchun, Zhang, Hong, 2011. Remote estimation of chlorophyll a in optically complex waters based on optical classification. Remote Sens. Environ. 115 (2), 725-737. https://doi.org/10. 1016/j.rse.2010.10.014.

Leeuw, Thomas, Boss, Emmanuel, 2018. The HydroColor app: above water measurements of remote sensing reflectance and turbidity using a smartphone camera. Sensors 18 (1), 256 Multidisciplinary Digital Publishing Institute.

Legendre, Pierre, 2014. Lmodel2: Model II Regression. R Package Version 1.7-2. Available at. http://CRAN.R-project.org/package $=$ lmodel2, Accessed date: 2 March 2015.

Lymburner, Leo, et al., 2016. Landsat 8: providing continuity and increased precision for measuring multi-decadal time series of total suspended matter. Remote Sens. Environ. 185, 108-118.

Malmqvist, Björn, Rundle, Simon D., Covich, Alan P., Hildrew, Alan G., Robinson, Christopher T., Townsend, Colin R., 2008. Prospects for streams and rivers: an ecological perspective. In: Aquatic Ecosystems: Trends and Global Prospects. Cambridge University Press, pp. 19-29.

Martins, Vitor, Barbosa, Claudio, de Carvalho, Lino, Jorge, Daniel, Lobo, Felipe, Novo, Evlyn, 2017. Assessment of atmospheric correction methods for Sentinel-2 MSI images applied to Amazon floodplain lakes. Remote Sens. 9 (4), 322. https://doi.org/ 10.3390/rs9040322. Multidisciplinary Digital Publishing Institute.

Matsuoka, A., Babin, M., Devred, E.C., 2016. A new algorithm for discriminating water sources from space: a case study for the southern Beaufort Sea using MODIS ocean color and SMOS salinity data. Remote Sens. Environ. 184, 124-138. http://www. sciencedirect.com/science/article/pii/S0034425716301997.

McCain, Charles, Hooker, Stanford, Feldman, Gene, Bontempi, Paul, 2006. Satellite data for ocean biology, biogeochemistry, and climate research. EOS Trans. Am. Geophys. Union 87 (34), 337-343 Wiley Online Library.

McClain, Charles, Meister, Gerhard, 2012. Mission Requirements for Future Ocean-colour Sensors. International Ocean-Colour Coordinating Group.

Mobley, Curtis D., 1999. Estimation of the remote-sensing reflectance from above-surface measurements. Appl. Opt. 38 (36), 7442-7455 Optical Society of America.

Mobley, Curtis D., Werdell, Jeremy, Franz, Bryan, Ahmad, Ziauddin, Bailey, Sean, 2016. Atmospheric Correction for Satellite Ocean Color Radiometry.

Mouw, Colleen B., Chen, Haidi, McKinley, Galen A., Effler, Steven, O'Donnell, David, Perkins, Mary Gail, Strait, Chris, 2013. Evaluation and optimization of bio-optical inversion algorithms for remote sensing of Lake Superior's optical properties. J. Geophys. Res. Oceans 118 (4), 1696-1714 Wiley Online Library.

Mouw, Colleen B., Greb, Steven, Aurin, Dirk, DiGiacomo, Paul M., Lee, Zhongping, Twardowski, Michael, Binding, Caren, Hu, Chuanmin, Ma, Ronghua, Moore, Timothy, 2015. Aquatic color radiometry remote sensing of coastal and inland waters: challenges and recommendations for future satellite missions. Remote Sens. Environ. 160, 15-30 Elsevier.

Muller-Karger, Frank E., Hestir, Erin, Ade, Christiana, Turpie, Kevin, Roberts, Dar A., Siegel, David, Miller, Robert J., Humm, David, Izenberg, Noam, Keller, Mary, 2018. Satellite sensor requirements for monitoring essential biodiversity variables of coastal ecosystems. Ecol. Appl. 28 (3), 749-760 Wiley Online Library.

Nechad, B., Ruddick, K.G., Neukermans, G., 2009. Calibration and validation of a generic multisensor algorithm for mapping of turbidity in coastal waters. In: Proc. of SPIE Vol, pp. 7473 (74730H-1).

Novoa, Stéfani, Doxaran, David, Ody, Anouck, Vanhellemont, Quinten, Lafon, Virginie, Lubac, Bertrand, Gernez, Pierre, 2017. Atmospheric corrections and multi-conditional algorithm for multi-sensor remote sensing of suspended particulate matter in low-to-high turbidity levels coastal waters. Remote Sens. 9 (1), 61 Multidisciplinary Digital Publishing Institute.

Olmanson, Leif G., Bauer, Marvin E., Brezonik, Patrick L., 2008. A 20-year landsat water clarity census of Minnesota's 10,000 lakes. Remote Sens. Environ. 112 (11), 4086-4097 Elsevier.

O'Reilly, John E., Stephane, Maritorena, Greg Mitchell, B., Siegel, David A., Carder, Kendall L., Garver, Sara A., Kahru, Mati, McClain, Charles, 1998. Ocean color chlorophyll algorithms for SeaWiFS. J. Geophys. Res. Oceans 103 (C11), 24937-24953 Wiley Online Library.

Overstreet, Brandon T., Legleiter, Carl J., 2017. Removing sun glint from optical remote sensing images of shallow rivers. Earth Surf. Process. Landf. 42 (2), 318-333. https:// doi.org/10.1002/esp.4063.

Pahlevan, Nima, Lee, Zhongping, Wei, Jianwei, Schaaf, Crystal B., Schott, John R., Berk, Alexander, 2014. On-orbit radiometric characterization of OLI (Landsat-8) for applications in aquatic remote sensing. Remote Sens. Environ. 154, 272-284 Elsevier.

Pahlevan, Nima, Sarkar, Sudipta, Franz, Bryan A., 2016. Uncertainties in coastal ocean color products: impacts of spatial sampling. Remote Sens. Environ. 181 (August), 14-26. https://doi.org/10.1016/j.rse.2016.03.022.

Pahlevan, Nima, Smith, Brandon, Binding, Caren, O'Donnell, David, 2017a. Spectral band adjustments for remote sensing reflectance spectra in coastal/inland waters. Opt. Express 25 (23), 28650-28667 Optical Society of America.

Pahlevan, Nima, Sarkar, S., Franz, B.A., Balasubramanian, S.V., He, J., 2017b. Sentinel-2 MultiSpectral Instrument (MSI) data processing for aquatic science applications: demonstrations and validations. Remote Sens. Environ. 201 (November), 47-56. https://doi.org/10.1016/J.RSE.2017.08.033. Elsevier.

Pahlevan, Nima, Schott, John R., Franz, Bryan A., Zibordi, Giuseppe, Markham, Brian, Bailey, Sean, Schaaf, Crystal B., Ondrusek, Michael, Greb, Steven, Strait, Christopher M., 2017c. Landsat 8 remote sensing reflectance (Rrs) products: evaluations, intercomparisons, and enhancements. Remote Sens. Environ. 190, 289-301. https://doi. org/10.1016/j.rse.2016.12.030.

Pahlevan, Nima, Chittimalli, Sandeep K., Balasubramanian, Sundarabalan V., Vellucci, Vincenzo, 2019. Sentinel-2/Landsat-8 product consistency and implications for monitoring aquatic systems. Remote Sens. Environ. 220, 19-29 Elsevier.

Pekel, Jean-François, Cottam, Andrew, Gorelick, Noel, Belward, Alan S., 2016. High-resolution mapping of global surface water and its long-term changes. Nature 540.7633, 418 APA.

Richter, Rudolf, Bachmann, Martin, Dorigo, Wouter, Muller, A., 2006. Influence of the adjacency effect on ground reflectance measurements. IEEE Geosci. Remote Sens. Lett. 3 (4), 565-569 IEEE.

Ricker, W.E., 1973. Linear regressions in fishery research. J. Fish. Res. Board Can. 30 (3), 409-434. https://doi.org/10.1139/f73-072. NRC Research Press.

Roesler, Collin, Uitz, Julia, Claustre, Hervé, Boss, Emmanuel, Xing, Xiaogang, Organelli, Emanuele, Briggs, Nathan, et al., 2017. Recommendations for obtaining unbiased chlorophyll estimates from in situ chlorophyll fluorometers: a global analysis of WET labs ECO sensors. Limnol. Oceanogr. Methods 15 (6), 572-585. https://doi.org/10. 1002/lom3.10185.

Roy, D.P., Wulder, M.A., Loveland, T.R., Woodcock, C.E., Allen, R.G., Anderson, M.C., Helder, D., et al., 2014. Landsat-8: science and product vision for terrestrial global 
change research. Remote Sens. Environ. 145 (April), 154-172. https://doi.org/10. 1016/j.rse.2014.02.001.

Ruddick, Kevin George, Ovidio, Fabrice, Rijkeboer, Machteld, 2000. Atmospheric correction of SeaWiFS imagery for turbid coastal and inland waters. Appl. Opt. 39 (6), 897-912 Optical Society of America.

Ruddick, Kevin, De Cauwer, Vera, Van Mol, Barbara, 2005. Use of the near infrared similarity reflectance spectrum for the quality control of remote sensing data. In: Remote Sensing of the Coastal Oceanic Environment. International Society for Optics and Photonics 5885:588501.

Ruddick, Kevin, De Cauwer, Vera, Park, Young-Je, Moore, Gerald, 2006. Seaborne measurements of near infrared water-leaving reflectance: the similarity spectrum for turbid waters. Limnol. Oceanogr. 51 (2), 1167-1179 Wiley Online Library.

Saba, V.S., Friedrichs, M.A.M., David, Antoine, Armstrong, R.A., Asanuma, I., Behrenfeld, M.J., Ciotti, A.M., Dowell, M., Hoepffner, N., Hyde, K.J.W., 2011. An Evaluation of Ocean Color Model Estimates of Marine Primary Productivity in Coastal and Pelagic Regions Across the Globe. Copernicus Publications.

Saraceno, John Franco, Pellerin, Brian A., Downing, Bryan D., Boss, Emmanuel, Bachand, Philip A.M., Bergamaschi, Brian A., 2009. High-frequency in situ optical measurements during a storm event: assessing relationships between dissolved organic matter, sediment concentrations, and hydrologic processes. J. Geophys. Res. Biogeosci. 114 (G4) (Wiley Online Library).

Sawakuchi, Henrique O., Neu, Vania, Ward, Nicholas D., Barros, Maria de Lourdes C., Valerio, Aline M., Gagne-Maynard, William, Cunha, Alan C., Less, Diani F.S., Diniz, Joel E.M., Brito, Daimio C., 2017. Carbon dioxide emissions along the Lower Amazon River. Front. Mar. Sci. 4, 76 Frontiers.

Seegers, Bridget N., Stumpf, Richard P., Schaeffer, Blake A., Loftin, Keith A., Werdell, P. Jeremy, 2018. Performance metrics for the assessment of satellite data products: an ocean color case study. Opt. Express 26 (6), 7404-7422 Optical Society of America.

Shi, Wei, Wang, Menghua, 2009. An assessment of the black ocean pixel assumption for MODIS SWIR bands. Remote Sens. Environ. 113 (8), 1587-1597 Elsevier.

Shi, Kun, Zhang, Yunlin, Zhu, Guangwei, Liu, Xiaohan, Zhou, Yongqiang, Xu, Hai, Qin, Boqiang, Liu, Ge, Li, Yunmei, 2015. Long-term remote monitoring of total suspended matter concentration in Lake Taihu using $250 \mathrm{~m}$ MODIS-aqua data. Remote Sens. Environ. 164, 43-56 Elsevier.

Slade, Wayne H., Boss, Emmanuel, Giorgio, Dall'Olmo, Rois Langner, M., Loftin, James, Behrenfeld, Michael J., Roesler, Collin, Westberry, Toby K., 2010. Underway and moored methods for improving accuracy in measurement of spectral particulate absorption and attenuation. J. Atmos. Ocean. Technol. 27 (10), 1733-1746.

Smith, Val H., 2003. Eutrophication of freshwater and coastal marine ecosystems a global problem. Environ. Sci. Pollut. Res. 10 (2), 126-139 Springer.

Spyrakos, Evangelos, O'Donnell, Ruth, Hunter, Peter D., Miller, Claire, Scott, Marian, Simis, Stefan G.H., Neil, Claire, Barbosa, Claudio C.F., Binding, Caren E., Bradt, Shane, 2018. Optical types of inland and coastal waters. Limnol. Oceanogr. 63 (2), 846-870 Wiley Online Library.

Sriwongsitanon, Nutchanart, Surakit, Kritsanat, Thianpopirug, Sansarith, 2011. Influence of atmospheric correction and number of sampling points on the accuracy of water clarity assessment using remote sensing application. J. Hydrol. 401 (3-4), 203-220 Elsevier.

Stadler, Philipp, Loken, Luke C., Crawford, John T., Schramm, Paul J., Sorsa, Kirsti, Kuhn, Catherine, Savio, Domenico, Striegl, Robert G., Butman, David, Stanley, Emily H., 2018. Spatial patterns of enzymatic activity in large water bodies: ship-borne measurements of beta-D-glucuronidase activity as a rapid indicator of microbial water quality. Sci. Total Environ. 651 (Pt 2), 1742-1752.

Sterckx, S., Knaeps, S., Kratzer, Susanne, Ruddick, K., 2015. SIMilarity Environment Correction (SIMEC) applied to MERIS data over inland and coastal waters. Remote Sens. Environ. 157, 96-110 Elsevier.

Sun, Deyong, Hu, Chuanmin, Qiu, Zhongfeng, Cannizzaro, Jennifer P., Barnes, Brian B., 2014. Influence of a red band-based water classification approach on chlorophyl algorithms for optically complex estuaries. Remote Sens. Environ. 155, 289-302 Elsevier.

Team, R. Core, 2017. R: A Language and Environment for Statistical Computing. R Foundation for Statistical Computing, Vienna, Austria.

Tebbs, E.J., Remedios, J.J., Harper, D.M., 2013. Remote sensing of chlorophyll-a as a measure of cyanobacterial biomass in lake bogoria, a hypertrophic, saline-alkaline, Flamingo Lake, using Landsat ETM + . Remote Sens. Environ. 135, 92-106 Elsevier.

Turner, P.A., Griffis, T.J., Baker, J.M., Lee, X., Crawford, J.T., Loken, L.C., Venterea, R.T., 2016. Regional-scale controls on dissolved nitrous oxide in the upper Mississippi River. Geophys. Res. Lett. April. https://doi.org/10.1002/2016GL068710.

USGS, 2018. Landsat 8 Surface Reflectance Code Product Guide.

Valente, André, Sathyendranath, Shubha, Brotas, Vanda, Groom, Steve, Grant, Michael, Taberner, Malcolm, Antoine, David, et al., 2016. A compilation of global bio-optical in situ data for ocean-colour satellite applications. Earth Syst. Sci. Data 8 (1), 235-252. https://doi.org/10.5194/essd-8-235-2016.

Valerio, Aline, Kampel, Milton, Vantrepotte, Vincent, Ward, Nicholas, Sawakuchi, Henrique, Fernanda, Diani, Less, Diani, et al., 2017. Assessment of remote sensing empirical algorithms to retrieve colored dissolved organic matter in the lower Amazon River. In: XVIII Proceedings of Brazilian Symposium on Remote Sensing. Brazilian Symposium on Remote Sensing - SBSR, Santos, SP.

Vanhellemont, Quinten, Ruddick, Kevin, 2014. Turbid wakes associated with offshore wind turbines observed with Landsat 8. Remote Sens. Environ. 145, 105-115 Elsevier.

Vanhellemont, Q., Ruddick, K., 2015. Advantages of high quality SWIR bands for ocean colour processing: examples from Landsat-8. Remote Sens. Environ. 161, 89-106.

Vanhellemont, Q., Ruddick, K., 2016. Acolite for Sentinel-2: aquatic applications of MSI imagery. In: Ouwehand, L. (Ed.), Proceedings of the Living Planet Symposium. vol. 740. 978-92-9221-305-3, pp. 55. ESA-SP. Prague, Czech Republic. http://odnature. naturalsciences.be/downloads/publications/2016 Vanhellemont ESALP.pdf.

Vanhellemont, Quinten, Ruddick, Kevin, 2018. Atmospheric correction of metre-scale optical satellite data for inland and coastal water applications. Remote Sens. Environ. 216, 586-597 Elsevier.

Vermote, Eric, Justice, Chris, Claverie, Martin, Franch, Belen, 2016. Preliminary analysis of the performance of the Landsat 8/OLI land surface reflectance product. Remote Sens. Environ. 185, 46-56. https://doi.org/10.1016/j.rse.2016.04.008.

Vörösmarty, Charles J., McIntyre, Peter B., Gessner, Mark O., Dudgeon, David, Prusevich, Alexander, Green, Pamela, Glidden, Stanley, Bunn, Stuart E., Sullivan, Caroline A., Liermann, C. Reidy, 2010. Global threats to human water security and river biodiversity. Nature 467 (7315), 555 Nature Publishing Group.

Wang, Menghua, 2010. Atmospheric correction for remotely-sensed ocean-colour products. In: Reports and Monographs of the International Ocean-Colour Coordinating Group (IOCCG).

Wang, Menghua, Shi, Wei, 2006. Cloud masking for ocean color data processing in the coastal regions. IEEE Trans. Geosci. Remote Sens. 44 (11), 3105-3196 IEEE.

Wang, Menghua, Shi, Wei, 2007. The NIR-SWIR combined atmospheric correction approach for MODIS ocean color data processing. Opt. Express 15 (24), 15722-15733. https://doi.org/10.1364/OE.15.015722. OSA.

Wang, Menghua, Shi, Wei, Jiang, Lide, 2012. Atmospheric correction using near-infrared bands for satellite ocean color data processing in the turbid western pacific region. Opt. Express 20 (2), 741-753 Optical Society of America.

Ward, Nicholas D., Sawakuchi, Henrique O., Richey, Jeffrey E., 2018. The Amazon River's Ecosystem-Where Land Meets the Sea. No. PNNL-SA-128535. Pacific Northwest National Lab (PNNL), Richland, WA (United States).

Ward, Nicholas D., Sawakuchi, Henrique O., Richey, Jeffrey E., 2018. The Amazon River's Ecosystem-Where Land Meets the Sea. Pacific Northwest National Lab. (PNNL), Richland, WA (United States).

Water, U N, 2009. Water in a Changing World, United Nations World Water Development Report 3. World Water Assessment Programme.

Wei, J., et al., 2018. An assessment of Landsat-8 atmospheric correction schemes and remote sensing reflectance products in coral reefs and coastal turbid waters. Remote Sens. Environ. 215, 18-32.

Werdell, P. Jeremy, Bailey, Sean W., 2005. An improved in-situ bio-optical data set for ocean color algorithm development and satellite data product validation. Remote Sens. Environ. 98 (1), 122-140 Elsevier.

Werdell, P. Jeremy, Proctor, Christopher W., Boss, Emmanuel, Leeuw, Thomas, Ouhssain, Mustapha, 2013. Underway sampling of marine inherent optical properties on the Tara oceans expedition as a novel resource for ocean color satellite data product validation. Methods Oceanogr. 7, 40-51 Elsevier.

Werdell, P. Jeremy, McKinna, Lachlan I.W., Boss, Emmanuel, Ackleson, Steven G., Craig, Susanne E., Gregg, Watson W., Lee, Zhongping, Maritorena, Stéphane, Roesler, Collin S., Rousseaux, Cécile S., 2018. An overview of approaches and challenges for retrieving marine inherent optical properties from ocean color remote sensing. Prog. Oceanogr. 160, 186-212.

Whitehead, P.G., Wilby, R.L., Battarbee, R.W., Kernan, M., Wade, Andrew John, 2009. A review of the potential impacts of climate change on surface water quality. Hydrol. Sci. J. 54 (1), 101-123 Taylor \& Francis.

Woodcock, Curtis E., Allen, Richard, Anderson, Martha, Belward, Alan, Bindschadler, Robert, Cohen, Warren, Gao, Feng, Goward, Samuel N., Helder, Dennis, Helmer, Eileen, 2008. Free access to Landsat imagery. Science 320 (5879), 1011 American Association for the Advancement of Science.

Zhang, Hankui K., Roy, David P., Yan, Lin, Li, Zhongbin, Huang, Haiyan, Vermote, Eric, Skakun, Sergii, Roger, Jean-Claude, 2018. Characterization of Sentinel-2A and Landsat-8 top of atmosphere, surface, and Nadir BRDF adjusted reflectance and NDVI differences. Remote Sens. Environ. 